\title{
Impacts of Microphysics Schemes and Topography on the Prediction of the Heavy Rainfall in Western Myanmar Associated with Tropical Cyclone ROANU (2016)
}

\author{
Khin Win Maw ${ }^{1,2}$ and Jinzhong Min $^{3}$ \\ ${ }^{1}$ School of Atmospheric Science, Nanjing University of Information Science and Technology, Nanjing, China \\ ${ }^{2}$ Department of Meteorology and Hydrology, Naypyitaw, Myanmar \\ ${ }^{3}$ Key Laboratory of Meteorological Disaster, Ministry of Education (KLME)/Joint International Research Laboratory of \\ Climate and Environment Change (ILCEC)/Collaborative Innovation Center on Forecast and Evaluation of Meteorological \\ Disasters (CIC-FEMD), Nanjing University of Information Science \& Technology, Nanjing 210044, China
}

Correspondence should be addressed to Jinzhong Min; minjz@nuist.edu.cn

Received 14 April 2017; Revised 3 June 2017; Accepted 27 June 2017; Published 25 September 2017

Academic Editor: Mario M. Miglietta

Copyright (C) 2017 Khin Win Maw and Jinzhong Min. This is an open access article distributed under the Creative Commons Attribution License, which permits unrestricted use, distribution, and reproduction in any medium, provided the original work is properly cited.

\begin{abstract}
The impacts of different microphysics and boundary schemes and terrain settings on the heavy rainfall over western Myanmar associated with the tropical cyclone (TC) ROANU (2016) are investigated using the Weather Research and Forecasting (WRF) model. The results show that the microphysics scheme of Purdue Lin (LIN) scheme produces the strongest cyclone. Six experiments with various combinations of microphysics and boundary schemes indicated that a combination of WRF Single-Moment 6-class (WSM6) scheme and Mellor-Yamada-Janjic (MYJ) best fits to the Joint Typhoon Warning Center (JTWC) data. WSM6-MYJ also performs the best for the track and intensity of rainfall and obtains the best statistics skill scores in the range of maximum rainfall intensity for 48-h. Sensitivity experiments on different terrain settings with Normal Rakhine Mountain (NRM), with Half of Rakhine Mountain (HRM), and Without Rakhine Mountain (WoRM) are designed with the use of WSM6-MYJ scheme. The track of TC ROANU moved northwestward in WoRM and HRM. Due to the presence of Rakhine Mountain, TC track moved into Myanmar and the peak rainfall occurred on the leeward side of the Mountain. In the absence of Rakhine Mountain, a shift in peak rainfall was observed in north side of the Mountain.
\end{abstract}

\section{Introduction}

The tropical cyclone (TC) damages the human lives and properties due to its violent wind, storm surge, and heavy rainfall, which is of concern to west coast of Myanmar. 6-7\% of the total numbers of global tropical cyclones begin over North Indian Ocean in the past 300 years, out of which $75 \%$ of TCs, leaving more than 5,000 deaths, are occurring in this region [1] and every two or three years, one severe TC made landfall over Myanmar (e.g., Mala, Nargis, and Giri). The number of landfall TCs has increased in the west coast of Myanmar since 1990s [2]. In particular, the west coast of Myanmar suffers from heavy rainfall and flood disasters caused by TCs and the interaction between Rakhine Mountain and monsoon [3]. The local TC-related rainfall forecast is challenging in the west coast of Myanmar because of the high altitude and the complex mesoscale topography. The average elevation of Rakhine Mountain is more than $2000 \mathrm{~m}$ (while the highest peak is close to $3000 \mathrm{~m}$ ).

With the speedy development in the numerical models and computing power, different high-resolution mesoscale models are applied for predictions of TC [4]. However, the prediction of track has been a difficult task for meteorologist. A number of studies for track forecasting over the Bay of Bengal and other basins had been carried out by using various models such as Weather Research and Forecasting (WRF) 
model, Quasi-Lagrangian Model (QLM), Fifth-Generation Mesoscale Model (MM5), Florida State University Global Spectral Model and Nested Regional Spectral Model (FSU GSM and NRSM), Geophysical Fluid Dynamics Laboratory (GFDL) model, and Australian Bureau of Meteorology Research Centre (BMRC) model [5]. For example, with MM5 model, [6] used two nested domains to investigate the role of parameterization of convection and planetary boundary layer (PBL) scheme on tropical cyclone intensification. MellorYamada (MY) planetary boundary layer (PBL) produced the strongest cyclone and the combination of MY and KainFritsch 2 scheme generated the best for intensity and track forecast. With WRF model, [7] used two three-way nested domains to investigate the role of vortex initialization and model spin-up time. The results showed that first $18-24 \mathrm{~h}$ of model spin-up time and weaker vortex produced the best forecast for intensity of the cyclone. Reference [8] used $30 \mathrm{~km}$ resolution for variations in physical parameterization which revealed that the combination of Kain-Fritsch cumulus convection, Mellor-Yamada-Janjic planetary boundary layer, and Purdue Lin cloud microphysics scheme produced the best for TC track forecast.

Dynamics and physical processes are very important in numerical models for understanding and forecast of TC [9]. Reference [10] revealed the sensitivity of TC development to cloud microphysics schemes in a hydrostatic model. Their results imply that the intensification rate and final intensity of a simulated tropical cyclone are sensitive to the detail of the cloud microphysics parameterization used in the numerical models. The cloud microphysical processes are a major portion of the latent heat release [11]. The energy at the ocean exchange and supply through the planetary boundary layer to the free atmosphere play an important role in the intensification of the TC [12]. Thus, the PBL and microphysics processes play an important role in the development of tropical cyclone and require to be represented in the WRF model for realistic predictions. Several studies revealed that the track and intensity prediction of tropical cyclone is sensitive to the cumulus convection, planetary boundary layer (PBL), and cloud microphysics parameterization schemes [6, 13-17].

The predictability of rainfall related to TCs relies on the accurate forecast of the TC track, which may be deflected by the complicated high topography [18]. The importance of Rakhine Mountain influences on land falling TCs over western Myanmar has been recognized. To our knowledge, there are no comprehensive high-resolution numerical simulations that have investigated the influence of Rakhine Mountain on Myanmar TCs. Therefore, the present study seeks to understand the simulation of the track and heavy rainfall over western Myanmar with different microphysics and planetary boundary layer schemes. Further experiments are carried out to investigate the topographic effects of Rakhine Mountain associated with the TC ROANU (2016) during the premonsoon.

A significant number of researchers have studied the influence of terrain on TC worldwide (e.g., [19-27]). For example, the prediction of the intensity variation and precipitation of TCs are a challenge due to interaction with TCs and Central Mountain Range (CMR) in Taiwan [21, 22, 27-29].
Moreover, the effect of Taiwan's topography on the track plays an important role in capturing the rainfall distribution in Taiwan by using a high-resolution mesoscale model [25].

The rest of this paper is organized as follows. Section 2 presents the overview of TC ROANU, Section 3 describes the data and methodology, and results of the sensitivity experiments and model simulations are detailed in Section 4 before conclusions are achieved in Section 5.

\section{Overview of Tropical Cyclone ROANU}

ROANU formed in the evening of 15 May 2016 over the southwest Bay of Bengal. Due to the influence of Intertropical Convergence Zone (ITCZ), the system gradually developed into a deep depression at 0300 UTC, 18 May. The system intensified into a cyclonic storm and named ROANU with a central pressure of $983 \mathrm{hPa}$ and maximum sustained wind speed of around 45 knots at 0000 UTC, 19 May. The TC ROANU made landfall on the southeast coast of Bangladesh near $22.6^{\circ} \mathrm{N} / 91.6^{\circ} \mathrm{E}$ at $1000 \mathrm{UTC}, 21 \mathrm{May}$, as cyclonic storm (CS) stage and weakened into a well-marked low pressure area over Myanmar and adjoining Nagaland and Manipur. ROANU's effect on Sri Lanka, India, Bangladesh, and Myanmar lasted from 15 to 22 May (Figure 1) [30]. Its track moved northeastwards, along the coast of Sri Lanka and east coast of India, which is different from climatology for Bay of Bengal cyclones during this period.

\section{Model, Data, and Methodology}

The nonhydrostatic mesoscale model WRF-ARW version 3.7 was used in the present study, which was developed by the National Center for Atmospheric Research (NCAR). Reference [31] revealed the detailed description of the model equations, physics, and dynamics. The present study used a single domain which has $840 \times 744$ grid points with horizontal grid spacing of $3 \mathrm{~km}$. It covers the Bay of Bengal and Myanmar region $\left(8.11^{\circ} \mathrm{N}-28.04^{\circ} \mathrm{N}\right.$ and $\left.77.39^{\circ} \mathrm{E}-101.22^{\circ} \mathrm{E}\right) \mathrm{cen}-$ tered at $18.36^{\circ} \mathrm{N}$ and $89.31^{\circ} \mathrm{E}$. There are 32 vertical levels from the surface to the $50-\mathrm{hPa}$ level. The initial and boundary conditions to simulate the TC ROANU are obtained from the NOAA National Operational Model Archive and Distribution System (NOMADS) global forecast system (GFS) dataset on resolution of $0.5^{\circ} \times 0.5^{\circ}$ grids and every six-hourly intervals. These datasets are available in the following link $\mathrm{ftp}$ ://nomads.ncdc.noaa.gov/GFS/Grid4/.

In order to investigate the sensitivity and characteristics of the simulated precipitation and vertical moisture profiles, the Yonsei University (YSU) [32] and MYJ [33] for the planetary boundary layer $(\mathrm{PBL})$ schemes, and further to understand the interaction between PBL parameterizations and precipitation, three different bulk microphysics (MP) schemes such as the Purdue Lin (LIN) scheme [34], the WRF Single-Moment 6-class (WSM6) [35], and the ETA Gridscale Cloud and Precipitation (ETA Ferrier) [36] were used in this study. The LIN and WSM6 schemes have a six-class single-moment scheme, which comprises the mixing ratios of water vapor $\left(q_{v}\right)$, cloud water $\left(q_{c}\right)$, cloud ice $\left(q_{i}\right)$, snow $\left(q_{s}\right)$, rain $\left(q_{r}\right)$, and graupel $\left(q_{g}\right)$. Reference [37] described 


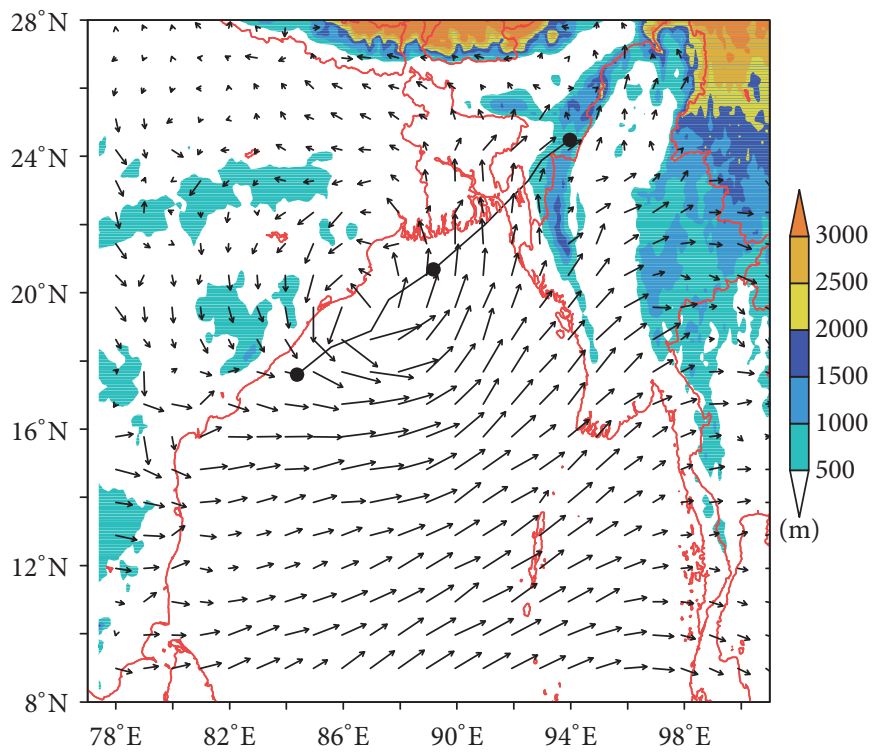

Figure 1: Domain for numerical experiments and initial background flows $\left(\mathrm{ms}^{-1}\right)$ at $850 \mathrm{hPa}$. The terrain height $(\mathrm{m})$ is shown with shades and the JTWC TC track is plotted.

the detailed explanation of the differences between LIN and WSM6. The ETA Ferrier scheme is composed of small ice crystals in the cirrus and larger ice particles in the form of snow, graupel, and sleet. Those ice particles are situated at the upper tropospheric clouds and lower levels, respectively. Other parameterizations chosen for this study include the Dudhia simple cloud-interactive shortwave radiation scheme [38], Rapid Radiative Transfer Model (RRTM) longwave radiation scheme [39], and Noah land surface scheme [40]. The cumulus parameterization is not applied in this study.

The observed tracks are obtained from the Joint Typhoon Warning Center (JTWC) for the comparison with the simulation. The 24-h rainfall data were obtained from the Department of Meteorology and Hydrology, Myanmar. The forecasting experiments are initialized at $72 \mathrm{~h}$ before the landing of TC. In this paper, a series of sensitivity experiments are carried out to simulate the TC ROANU for the track, intensity, and time of landfall to estimate the WRF model performance with different initial conditions. There are totally six experiments with different parameterization schemes of PBL and MP to investigate the suitable combination of physical processes. Initially three initial times such as depression stage (18 May), at the beginning of cyclonic storm stage (19 May), and before landfall of the cyclonic storm stage (20 May) are carried out with variations of three microphysics schemes and two PBL schemes. Thereafter, the suitable combination of the parameterization schemes and the initial time are used in following terrain experiment. Different parameterization sensitivity experiments are illustrated in Table 1.

The precipitation analysis is performed by using the Root Mean Square Error (RMSE) between the observed precipitation value, $O$, and the simulated precipitation value, $S$, for 91 stations, $N$, over Myanmar. The calculation of RMSE is shown in
TABLE 1: Physical parameterization scheme used in each numerical experiment.

\begin{tabular}{lcc}
\hline Microphysics schemes & PBL schemes & Initial time \\
\hline LIN & MYJ & 18 May 2016 \\
Ferrier & MYJ & 18 May 2016 \\
WSM6 & MYJ & 18 May 2016 \\
LIN & YSU & 18 May 2016 \\
Ferrier & YSU & 18 May 2016 \\
WSM6 & YSU & 18 May 2016 \\
LIN & MYJ & 19 May 2016 \\
Ferrier & MYJ & 19 May 2016 \\
WSM6 & MYJ & 19 May 2016 \\
LIN & YSU & 19 May 2016 \\
Ferrier & YSU & 19 May 2016 \\
WSM6 & YSU & 19 May 2016 \\
LIN & MYJ & 20 May 2016 \\
Ferrier & MYJ & 20 May 2016 \\
WSM6 & MYJ & 20 May 2016 \\
LIN & YSU & 20 May 2016 \\
Ferrier & YSU & 20 May 2016 \\
WSM6 & YSU & 20 May 2016 \\
\hline
\end{tabular}

$$
\operatorname{RMSE}=\sqrt{\left(\frac{1}{N}\right) \sum_{1}^{N}(S-O)^{2}}
$$

The statistical skills in the prediction can be expected with a precipitation threshold through the contingency table as shown in Table 2. Precipitation contingency table has four elements such as hit $(\mathrm{H})$, miss (M), false alarms (F), and none event which hold the number of observation stations 
TABLE 2: Contingency table for categorical verification scores.

\begin{tabular}{lccc}
\hline & & \multicolumn{2}{c}{ Observed } \\
& & Rain & Nonevent \\
\hline \multirow{2}{*}{ Simulated } & Rain & Hit & False alarms \\
& Nonevent & Miss & None \\
\hline
\end{tabular}

in which the observation and simulation exceed or fail to exceed a rainfall threshold. $H$ is defined as the correct forecast of rainfall occurrence. For example, for a rainfall threshold of 1-20 mm, if there was $20 \mathrm{~mm}$ of observed rainfall at an observation station and $22 \mathrm{~mm}$ of simulated rainfall (nonevent) at the same observation station, this would be a miss and count by one in miss counter. $N$ is defined as the total number of observation stations. The variable $E$, the Bias Score (BS), and Equitable Threat Score (ETS) are calculated by using the number of hits, misses, and false alarms events from the contingency table. The calculation of the $E, B S$, and ETS is shown in

$$
\begin{aligned}
E & =\frac{(H+F) \times(H+M)}{N} \\
\mathrm{BS} & =\frac{(H+F)}{(H+M)} \\
\mathrm{ET} & =\frac{(H-E)}{(H+M+F-E)} .
\end{aligned}
$$

The perfect forecast has BS value 1 and that means prediction is unbiased. If $\mathrm{BS}<1$, it means underprediction, and BS $>1$ means overprediction. BS $=0$ refers to no skill, and BS varies from 0 to $\infty$. An ETS of 1 indicates perfect skill, and ETS $\leq 0$ means that prediction has no skill. ETS varies between $-1 / 3$ and 1 .

\section{Results and Discussions}

In this study, a total of 6 experiments were carried out to investigate the sensitivity of two kinds of physical parameterization schemes. Further the study has also examined the Rakhine Mountain effect with the TC ROANU by using the combination of fit scheme.

\subsection{Sensitivity to Microphysics Parameterization Schemes.} The WRF model is applied for the prediction of TC ROANU with three microphysics schemes, two PBL schemes, and different initial times in order to evaluate the performance of the model in terms of track. Figure 2 depicts the track prediction of TC ROANU in three different microphysics schemes and two different planetary boundary layer schemes with three different initial conditions. The first simulation is based on deep depression stage which started at 18 May 2016. The result of the track does not reach the end of the observed land fall place (Figure 2(a)). The second simulation is based on the beginning of the cyclonic storm stage (19 May 2016) of which the track ended in the water (Figure 2(b)). The third simulation is based on cyclonic storm stage before landfall on 20 May 2016 of which the track captures the observed landfall position (Figure 2(c)). Based on the above result 20 May is selected for suitable initial time as in Figure 2(c). In Figure 2(c), the model simulated 48-h track forecast from 0000 UTC 20 May to 0000 UTC 22 May 2016 at every 6$\mathrm{h}$ intervals. It is pointed out that all the simulations lead to landfall over Bangladesh, where it actually occurred. Except LIN-YSU scheme, all the simulations predicted landfall on 2109 UTC at Bangladesh coast. It was very close to the actual landfall time on 2110 UTC. Only LIN-YSU scheme delays $3 \mathrm{~h}$ of actual landfall time. The simulated tracks are in good agreement with the observed track in terms of landfall time and location of landfall. Thus 48-hour simulation was the best performance for the model. The result is consistent with the study of [41].

This group comprises the experiments for TC ROANU explaining the impact of three different microphysical parameterization schemes (Ferrier, LIN, and WSM6) on track and intensity of the cyclone with MYJ and YSU as PBL. Figures 3 and 4 show the tracks, time evolution of track error, and intensity (CSLP and MSW) variation along with the JTWC observations for cyclone ROANU. These sensitivity experiments show insignificant impact on the track of cyclone ROANU. The experiments track moved eastward in the beginning; thereafter the track is overlapped with the JTWC observed track. All the tracks of the experiments moved in the northeast direction and could capture the first landfall position and deviated at the second landfall position. In MP schemes, the track of the LIN with MYJ and YSU as PBL scheme moved a bit northward compared with the observed JTWC track while track of Ferrier moved a bit southward. The track of the WSM6 scheme moved southward in MYJ and the track in YSU as PBL scheme moved northward compared with the observed JTWC track (Figures 3(a) and 4(a)). The average track error for LIN, Ferrier, and WSM6 is 64, 59, and $60 \mathrm{~km}$ with MYJ scheme (Figure $3(\mathrm{~b})$ ) and 58, 63, and $70 \mathrm{~km}$ with YSU scheme (Figure 4(b)) as PBL, respectively. The MP schemes have more impact on the track error. Time evolutions of the storm intensity in terms of CSLP and MSW for ROANU are shown in Figures 3(c) and 3(d). All the results based on the experiments that overpredicted the cyclone intensity are presented. In these experiments, the predeepening period was about $12 \mathrm{~h}$ with subsequent deepening up to $18-36 \mathrm{~h}$. The experiment with the LIN scheme produced the strongest cyclone, with a CSLP of $960 \mathrm{hPa}$. The mature stage of the cyclone varied between $6 \mathrm{~h}$ in WSM 6 and Ferrier and $12 \mathrm{~h}$ in LIN schemes. It is related to the maximum wind speed obtained with the different schemes varied from 32 to $37 \mathrm{~ms}^{-1}$. The maximum rate of intensification of LIN scheme showed that the sudden deepening occurred with a pressure drop of $24 \mathrm{hPa}$ in $18 \mathrm{~h}$ and other schemes were able to give a pressure fall of $13 \mathrm{hPa}$ (WSM6) and $10 \mathrm{hPa}$ (Ferrier), respectively, during the time interval from 1800 UTC 21 May to 1200 UTC 22 May. The JTWC reported that the estimated pressure drop was $3 \mathrm{hPa}$ in $6 \mathrm{~h}$ during the mature stage of the cyclone from 1800 UTC 21 May to 0000 UTC 22 May.

The LIN scheme shows higher intensity (simulated CSLP is $960 \mathrm{hPa}$ ) than Ferrier and WSM6. The CSLP of LIN with $\mathrm{MYJ}$ and YSU as PBL scheme has overpredicted the strongest cyclone intensity compared with other two MP schemes. The 


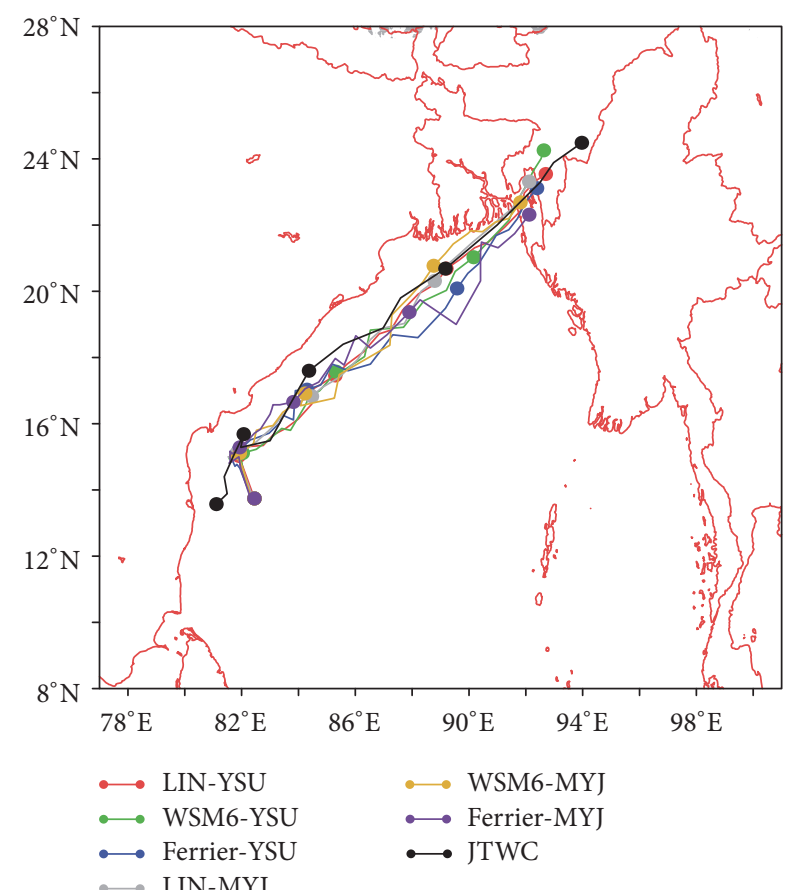

(a)

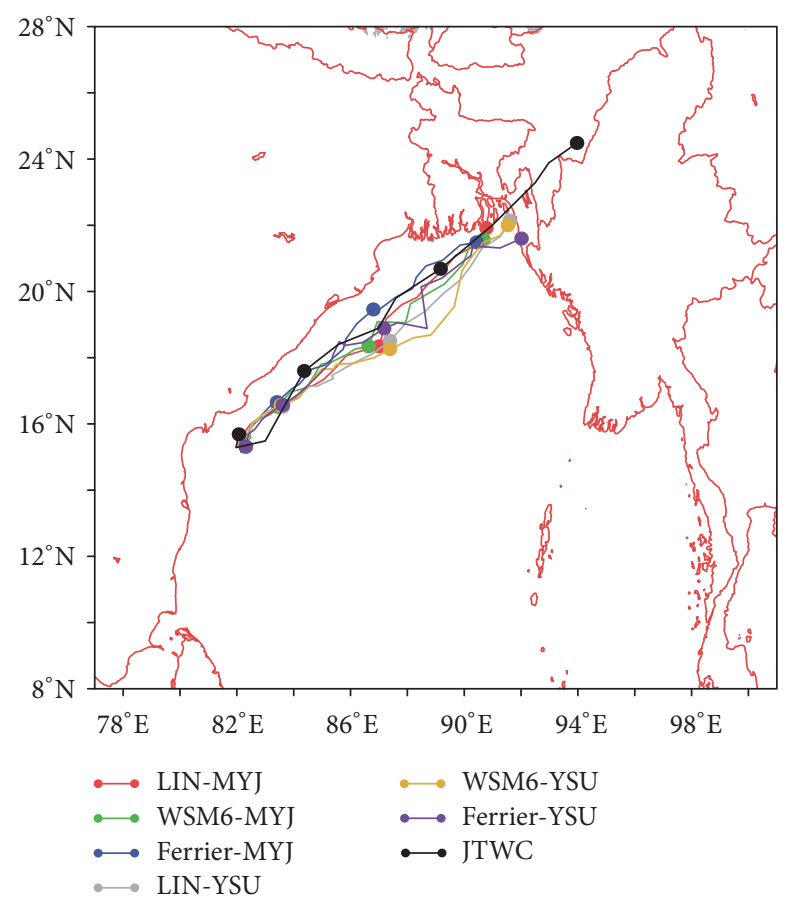

(b)

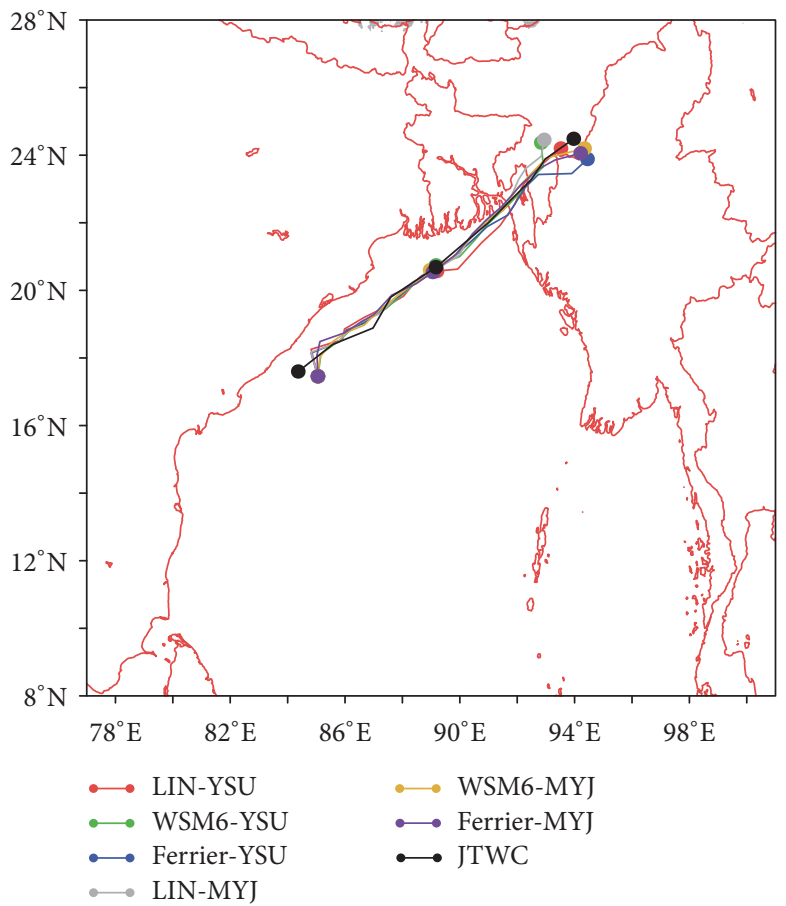

(c)

FIGURE 2: Different initial conditions of tropical cyclone ROANU track starting from 0000 UTC (a) 18 May, (b) 19 May, and (c) 20 May to 22 May 2016 with three microphysics schemes and two planetary boundary layer schemes.

results from Ferrier and WSM6 scheme are close to each other but cannot capture the observed intensity. It is pointed out that the intensity of cyclone ROANU is affected by MP schemes. References [41, 42] demonstrated that FerrierYSU schemes could capture well the track forecasting; it is consistent with the present study. LIN microphysics scheme overpredicted the cyclone intensity in the present study which is inconsistent with the earlier studies.

To understand the different behavior of the MP schemes for cyclone ROANU, the vertical profiles of an area averaged 


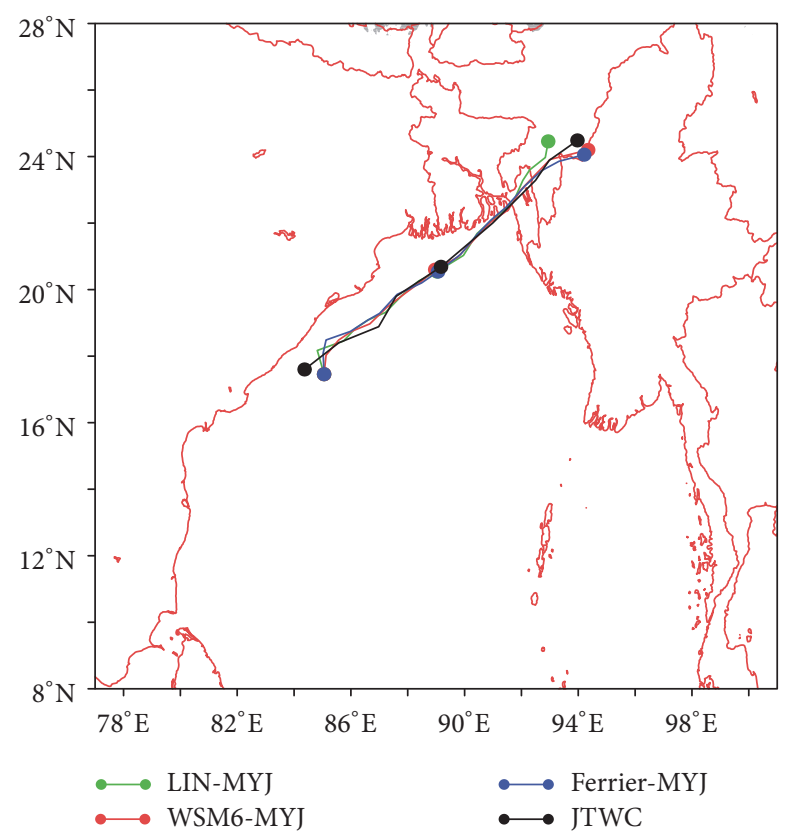

(a)

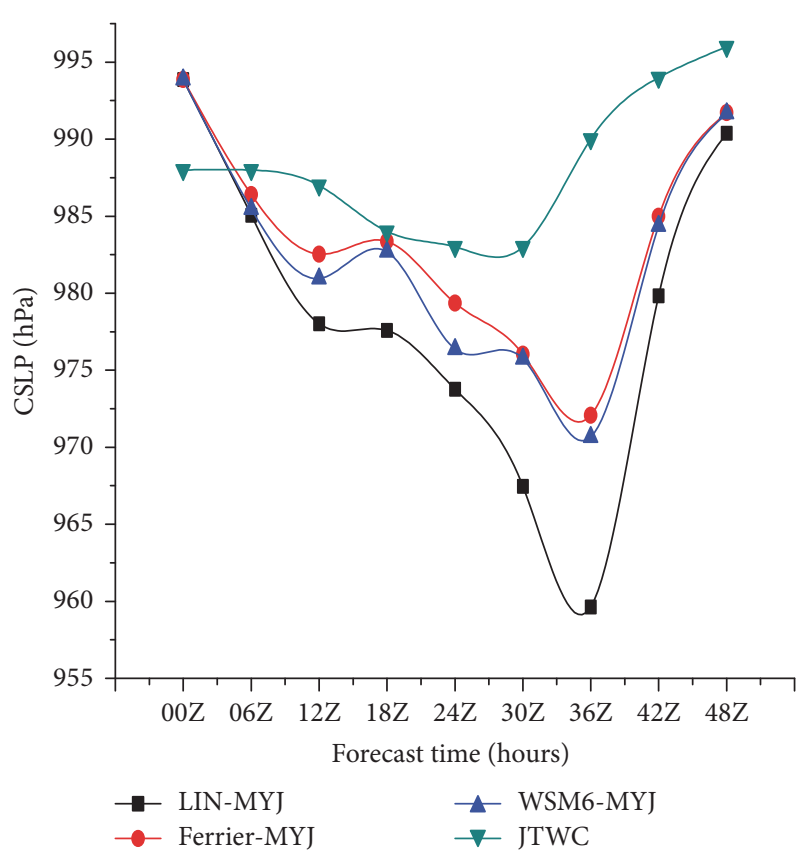

(c)

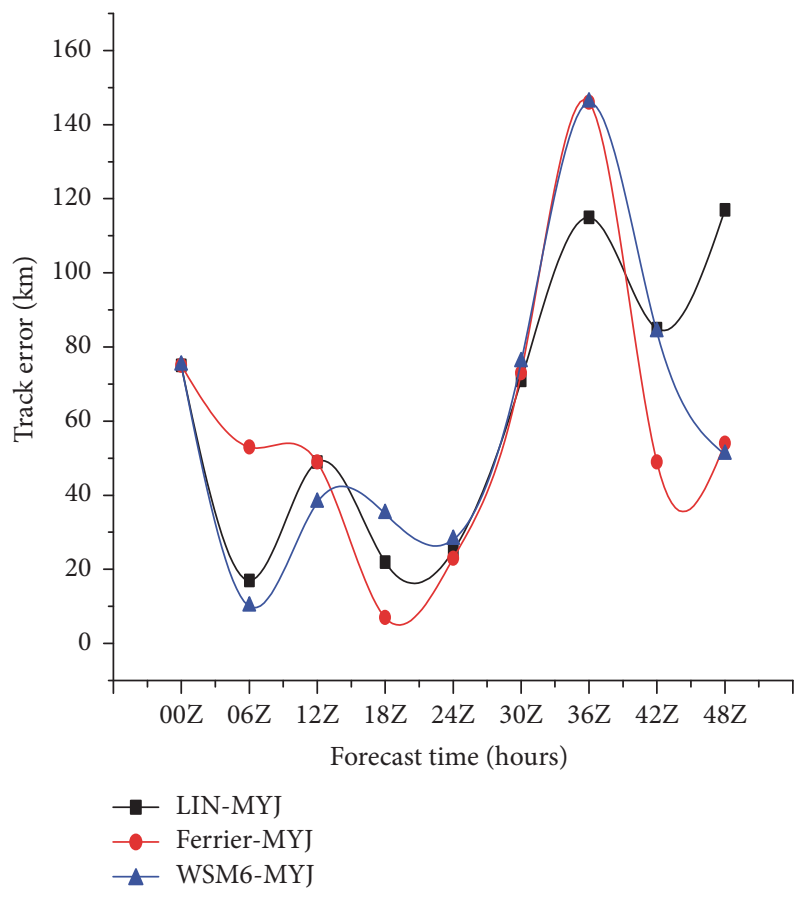

(b)

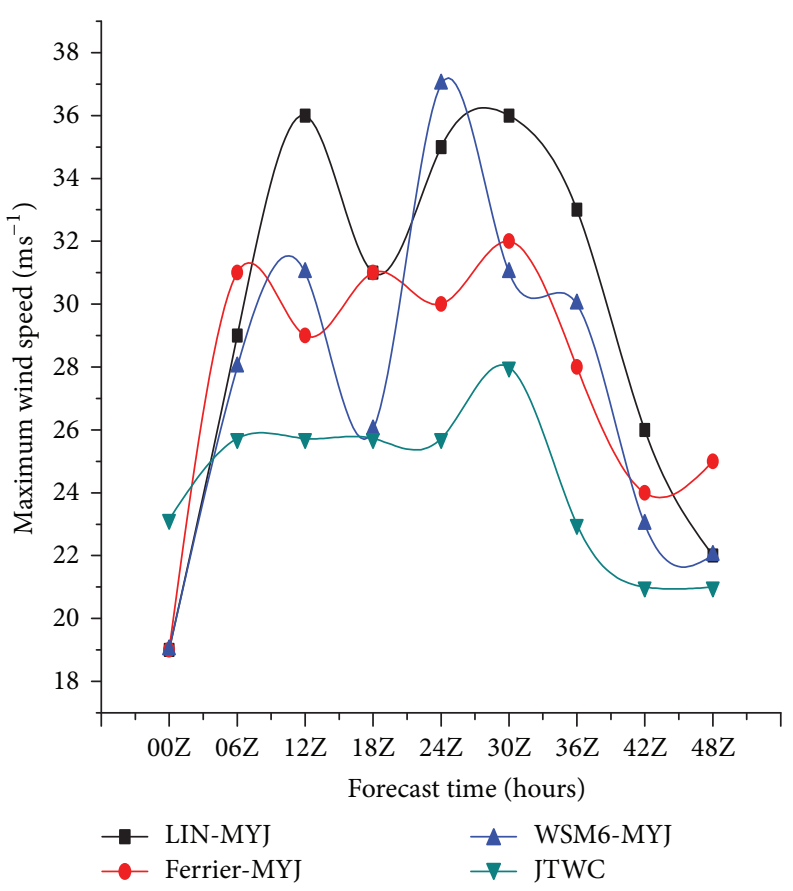

(d)

FIGURE 3: (a) Model simulated tracks, (b) forecast track error, (c) time series plot of minimum central sea level pressure (CSLP) in hPa, and (d) time series plot of maximum surface winds (MSW) in $\mathrm{ms}^{-1}$ for MYJ as planetary boundary layer (PBL) scheme experiment with LIN, Ferrier, and WSM6 in microphysics (MP) schemes along with JTWC best track, CSLP, and MSW data for tropical cyclone ROANU. The time interval of track and intensity is $6 \mathrm{~h}$.

mixing ratio over cyclone center region $\left(21-22^{\circ} \mathrm{N}, 88-92^{\circ} \mathrm{E}\right)$ during the 24-h period of 20-21 May 2016 are plotted in Figure 5. The frozen hydrometeors consist of ice, snow, and graupel and the liquid hydrometeors consist of rain and cloud water. The MP scheme of LIN indicates that strongest storm warm rain has produced a significant decrease of graupel and snow in the upper troposphere and large amount of rain water and cloud water in the lower troposphere compared 


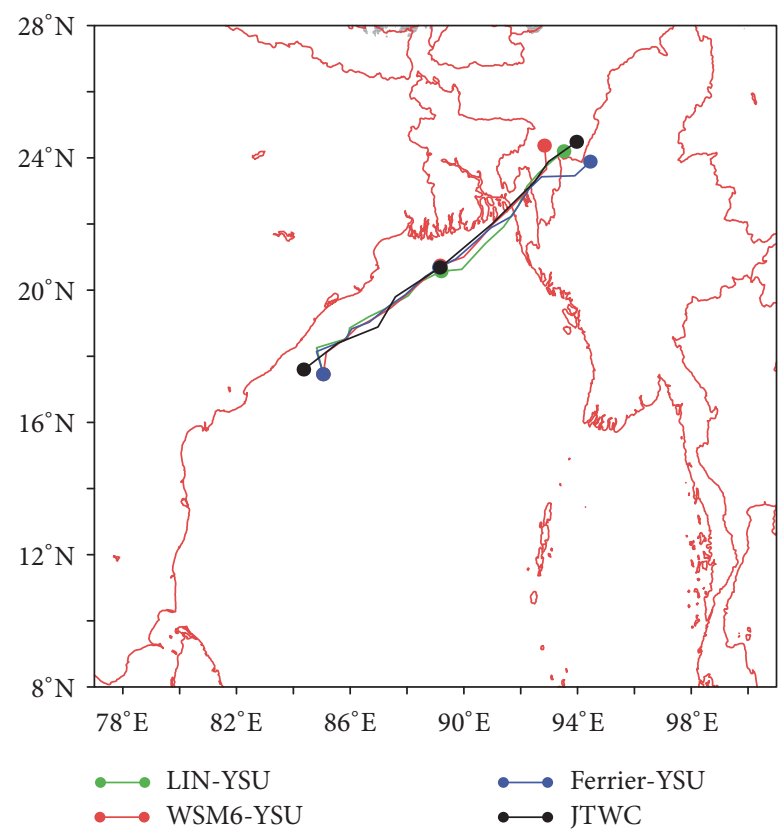

(a)

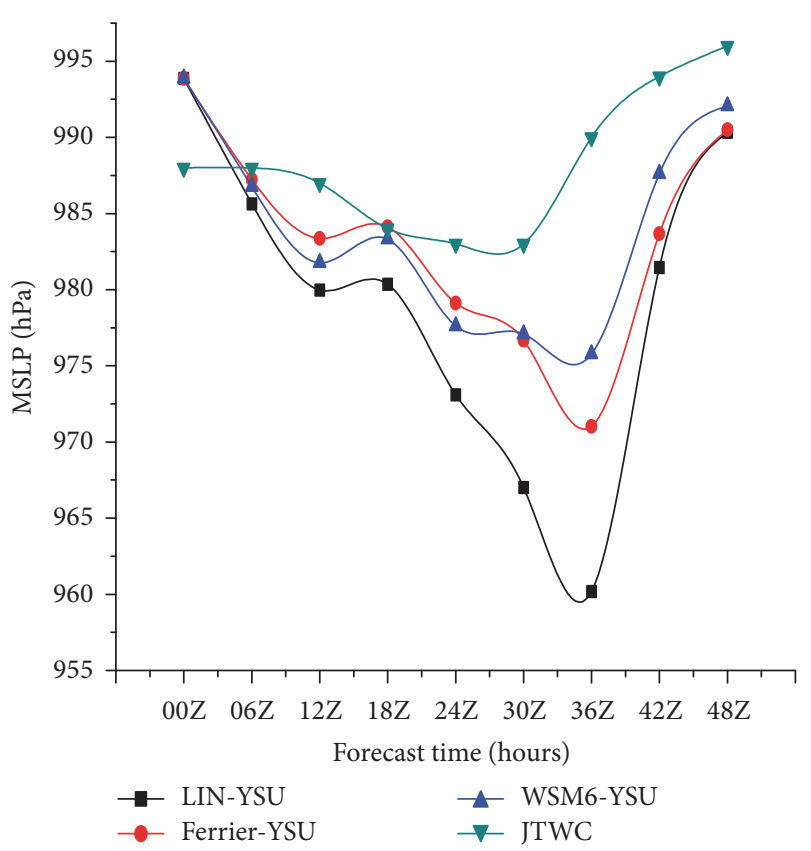

(c)

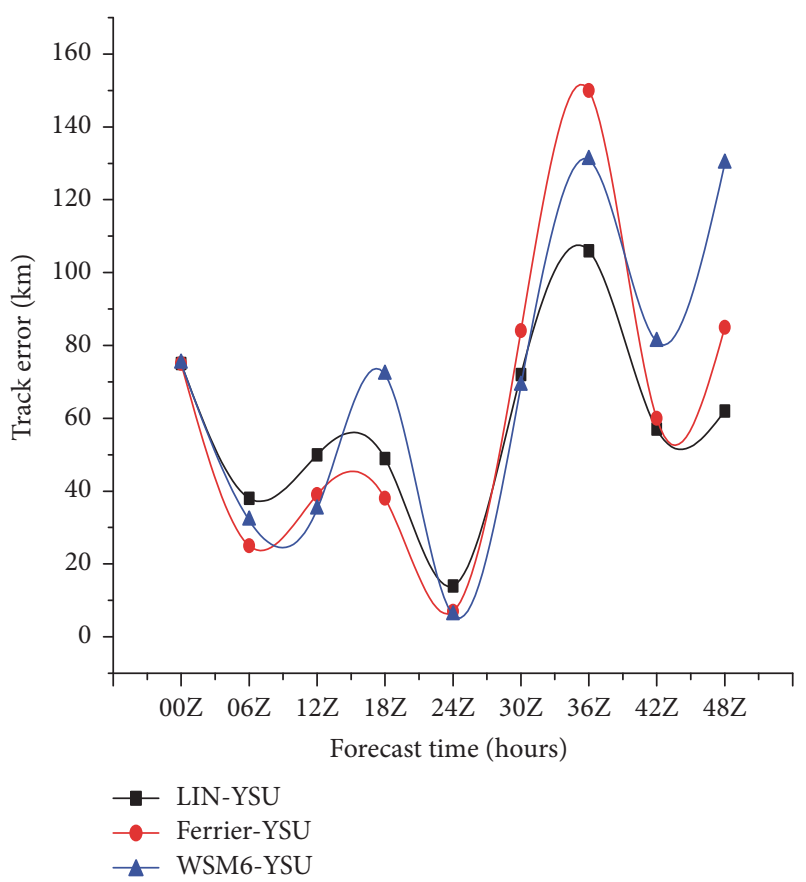

(b)

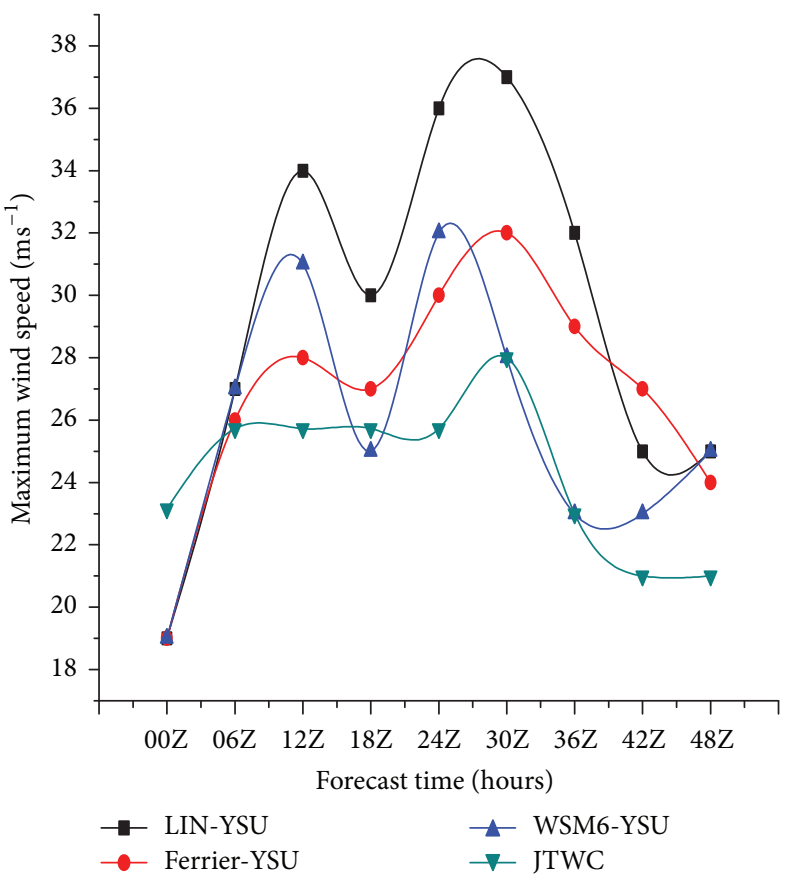

(d)

FIGURE 4: (a)-(d) Same as Figures 3(a)-3(d) but for experiments with different MP with YSU as PBL scheme sensitivity for tropical cyclone ROANU.

to Ferrier and WSM6 schemes (Figures 5(a) and 5(d)). Due to less hydrometeor, the storm obtained from LIN scheme has intense core of updrafts in the eye wall region, which helps in latent heat release (warm core) and facilitating its intensification. It appears that, in the case of Ferrier and WSM6, large accumulation of frozen hydrometeors such as ice, snow, and graupel in mid-troposphere results in slowing down the vertical acceleration of the intense updrafts in the eye wall of the storm, which might be responsible for inhibiting the storm intensification (Figures 5(b), 5(c), 5(e), and $5(\mathrm{f})$ ). Further, the precipitating cloud water and rain water are more pronounced at low levels. It is in good agreement with the maximum intensity of precipitation. The WSM6 scheme produced slightly higher concentration of frozen and 

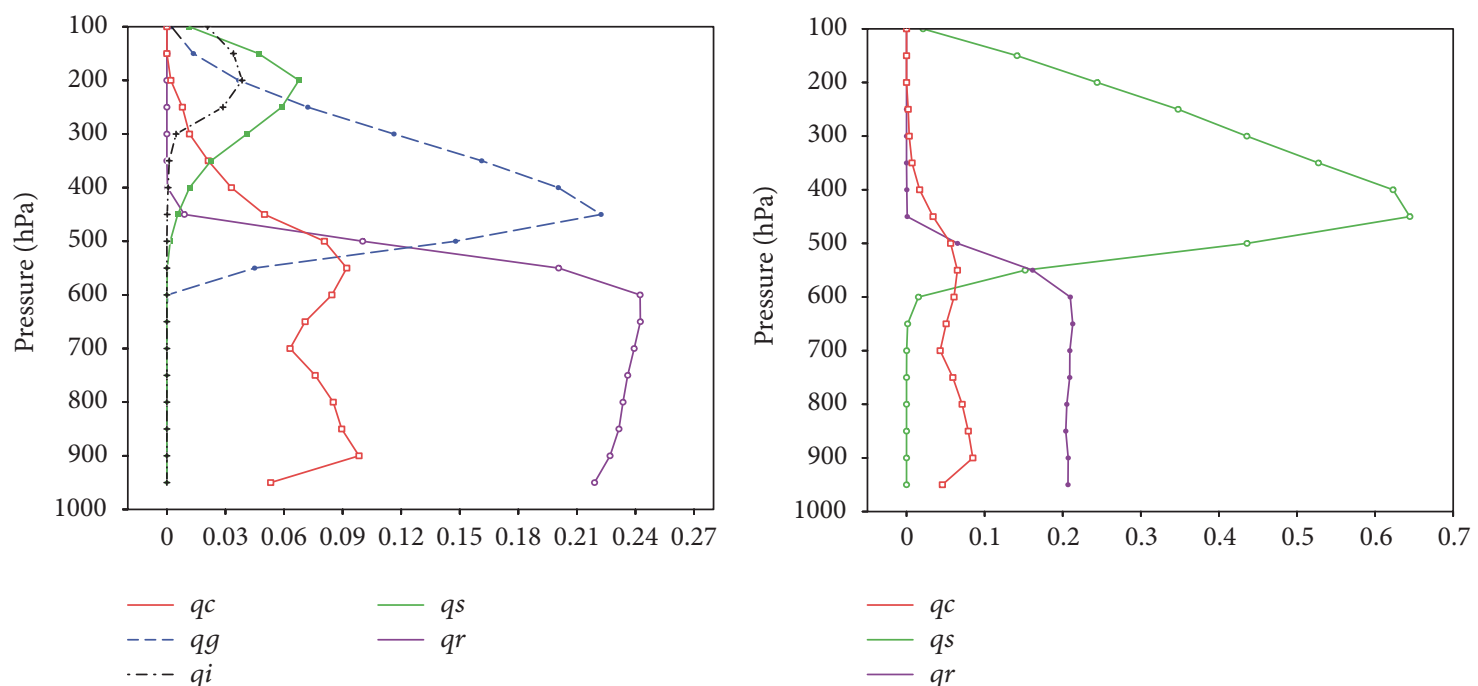

(a)
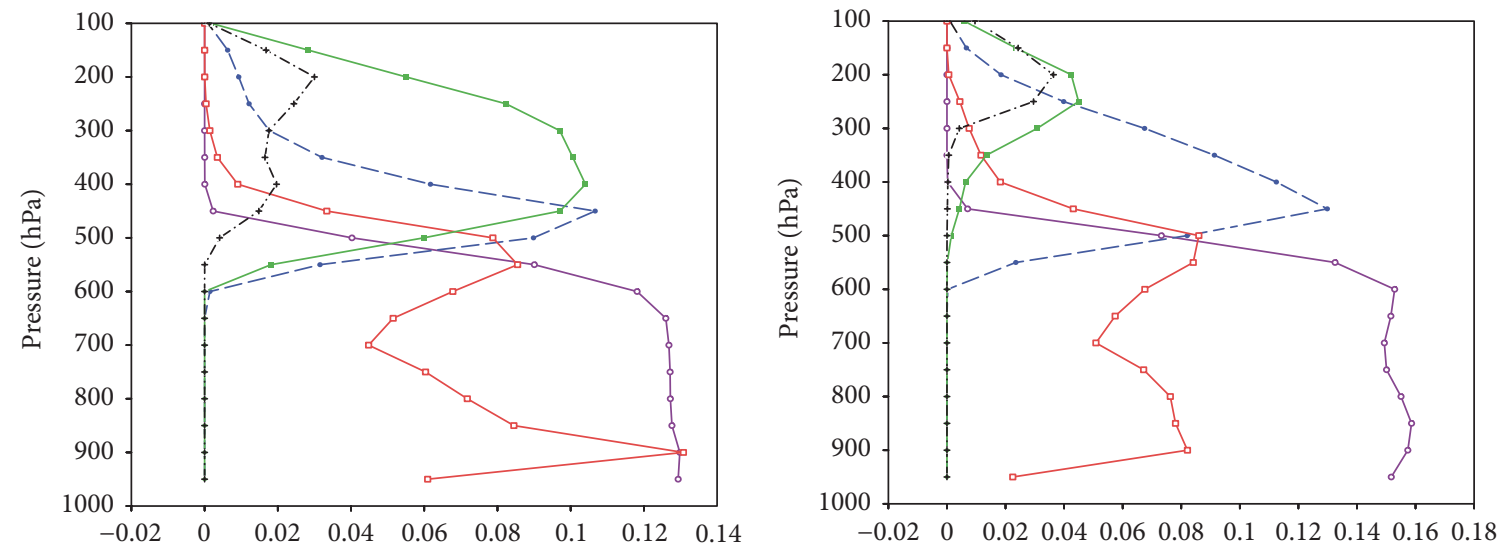

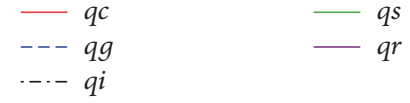

(c)

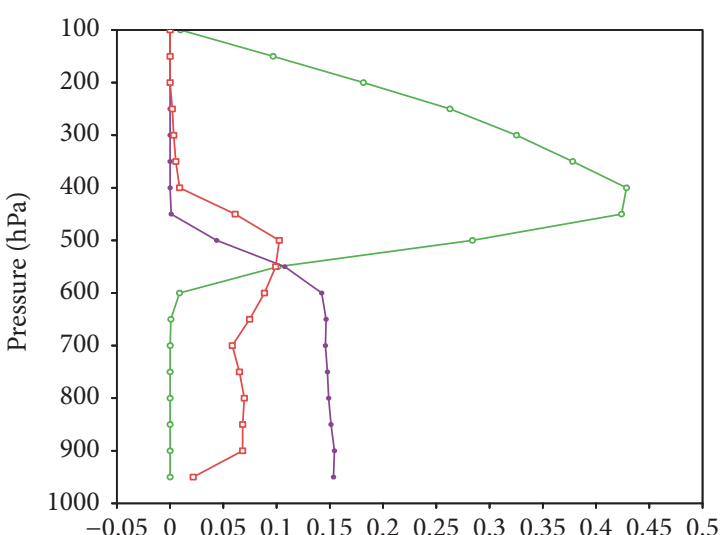

$-q c$
$-q s$
$-q^{r}$

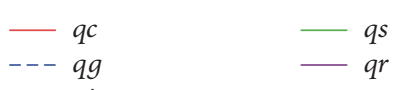

(d)

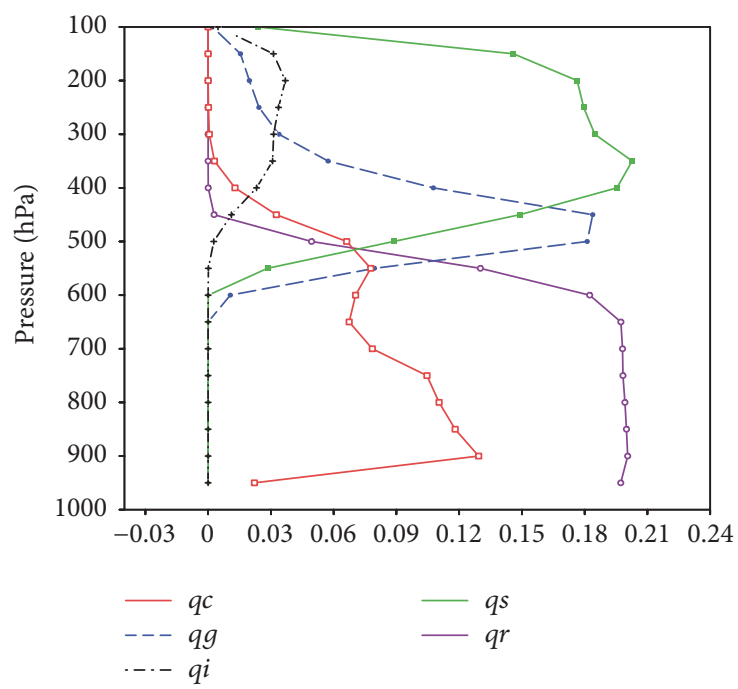

(f)

FIgURE 5: Vertical distribution of hydrometeors obtained from the combination of (a) LIN-MYJ, (b) Ferrier-MYJ, (c) WSM6-MYJ, (d) LINYSU, (e) Ferrier-YSU, and (f) WSM6-YSU schemes, averaged over the cyclone center area $21-22^{\circ} \mathrm{N}, 88-92^{\circ} \mathrm{E}$, during the $24 \mathrm{~h}$ period of $20-21$ May 2016. 


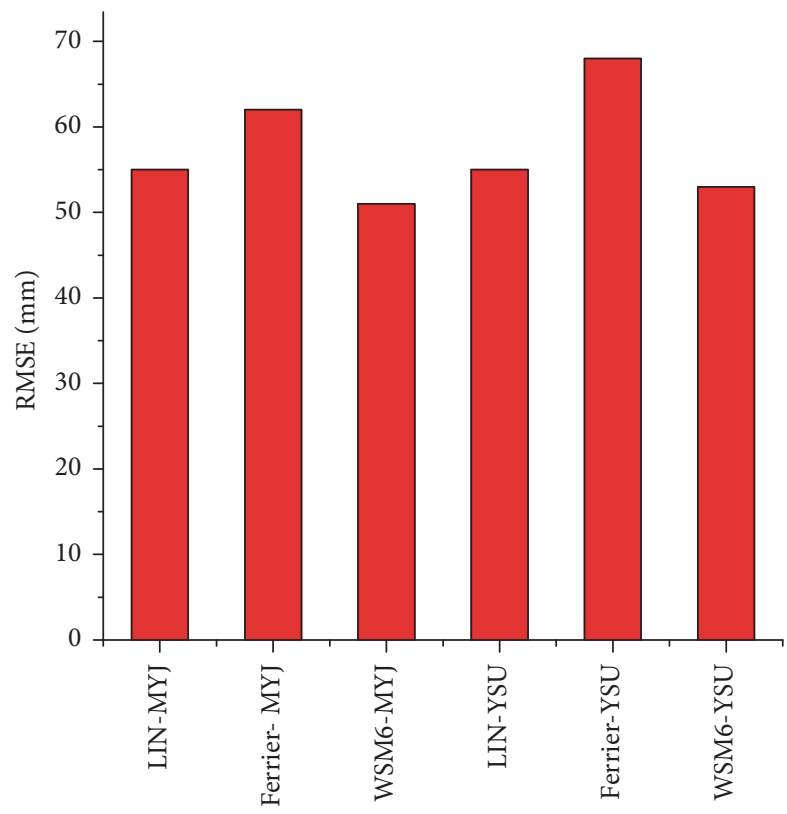

(a)

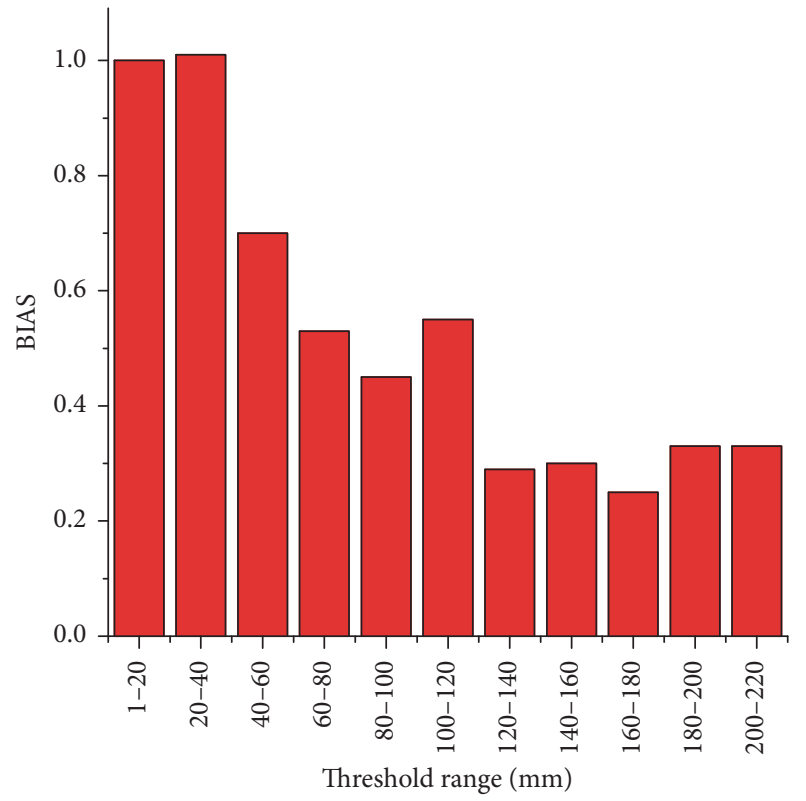

(b)

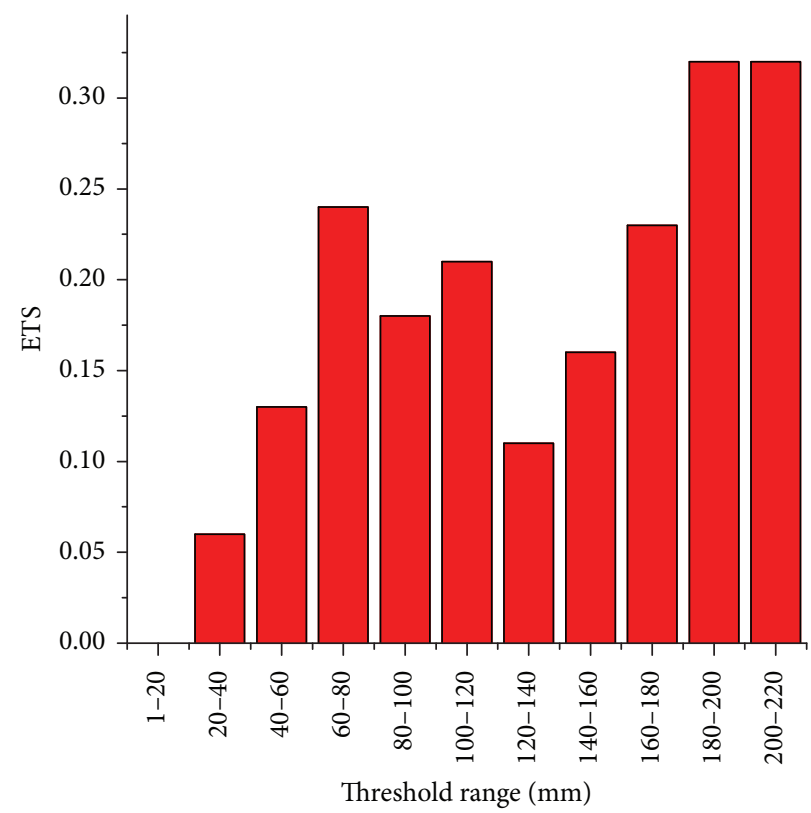

(c)

Figure 6: (a) The Root Mean Square Error (RMSE) of 48-h accumulated precipitation for different combination schemes. (b) Bias Score (BS) and (c) Equitable Threat Score (ETS) for the combination of WSM6-MYJ scheme for tropical cyclone ROANU.

liquid hydrometeors than LIN scheme. It indicates that the frozen hydrometeors contribute in the melting process and it increases the liquid hydrometeors at low levels. Thus the intensity of precipitation and distribution is affected by MP and PBL schemes.

In order to illustrate the impact of the different model physics configurations on quantitative results, 48-h rainfall amounts were verified against the model output based on the observational-model pair dataset from the 91 available stations as shown in Table 3. Each pair gives an error value from the calculation of Root Mean Square Error (RMSE) (Figure 6(a)). The combination of WSM6 with MYJ and YSU in PBL scheme has the lowest error and Ferrier has the highest error a s shown in Table 4. MP scheme of WSM6 with MYJ has lower error than YSU as PBL scheme. Thus, the combination of WSM6-MYJ scheme is selected as the suitable scheme of TC ROANU. The statistical skill scores of Bias Score (BS) and Equitable Thread Score (ETS) are calculated by using the precipitation threshold values from the simulation of WSM6-MYJ schemes as shown in Table 5. 
TABLE 3: 91 stations of observed and simulated precipitation (mm) for 21-22 May 2016.

\begin{tabular}{|c|c|c|c|c|c|c|c|}
\hline Stations & OBS & PLIN-MYJ & Ferrier-MYJ & WSM6-MYJ & PLIN-YSU & Ferrier-YSU & WSM6-YSU \\
\hline Putao & 83 & 16 & 40 & 23 & 45 & 34 & 20 \\
\hline Myitkyna & 84 & 11 & 23 & 19 & 13 & 16 & 29 \\
\hline Bhamo & 19 & 16 & 47 & 25 & 25 & 19 & 17 \\
\hline Machanbaw & 67 & 15 & 32 & 17 & 18 & 31 & 23 \\
\hline Hsipaw & 42 & 42 & 33 & 15 & 24 & 51 & 27 \\
\hline Lashio & 17 & 32 & 41 & 66 & 44 & 44 & 31 \\
\hline Taunggyi & 21 & 25 & 28 & 18 & 18 & 25 & 17 \\
\hline Kengtung & 1 & 8 & 3 & 7 & 2 & 8 & 7 \\
\hline Nansam & 8 & 22 & 92 & 43 & 35 & 93 & 48 \\
\hline Pinlaung & 60 & 31 & 92 & 29 & 55 & 57 & 25 \\
\hline Heho & 15 & 16 & 27 & 22 & 12 & 19 & 25 \\
\hline Mindat & 74 & 72 & 47 & 66 & 79 & 87 & 49 \\
\hline Hakha & 88 & 76 & 100 & 157 & 152 & 141 & 119 \\
\hline Palatwa & 163 & 170 & 219 & 103 & 214 & 111 & 90 \\
\hline Hkamti & 138 & 142 & 147 & 97 & 98 & 125 & 84 \\
\hline Homalin & 254 & 188 & 229 & 230 & 207 & 123 & 227 \\
\hline Katha & 40 & 64 & 79 & 42 & 60 & 46 & 33 \\
\hline Mawlaik & 67 & 74 & 139 & 111 & 111 & 118 & 107 \\
\hline Kalaywa & 79 & 63 & 52 & 43 & 52 & 73 & 63 \\
\hline Kalay & 43 & 85 & 145 & 98 & 118 & 98 & 86 \\
\hline Kanbalu & 14 & 48 & 43 & 50 & 64 & 27 & 62 \\
\hline Shwebo & 12 & 48 & 18 & 38 & 32 & 32 & 42 \\
\hline Monywa & 18 & 67 & 46 & 38 & 19 & 44 & 15 \\
\hline Sagaing & 3 & 27 & 31 & 22 & 26 & 41 & 35 \\
\hline Maymyo & 50 & 17 & 35 & 32 & 33 & 34 & 42 \\
\hline Mandalay & 22 & 34 & 30 & 22 & 17 & 37 & 31 \\
\hline Meiktila & 25 & 52 & 36 & 45 & 25 & 41 & 68 \\
\hline Moekok & 31 & 44 & 99 & 45 & 33 & 66 & 41 \\
\hline Myingyan & 24 & 40 & 44 & 29 & 49 & 69 & 44 \\
\hline Nyaungoo & 52 & 28 & 29 & 30 & 27 & 86 & 23 \\
\hline Kyaukse & 14 & 26 & 36 & 30 & 30 & 23 & 22 \\
\hline Tatkon & 14 & 63 & 33 & 15 & 20 & 40 & 27 \\
\hline Yezin & 34 & 34 & 48 & 48 & 27 & 35 & 132 \\
\hline Pyinmana & 40 & 87 & 27 & 31 & 20 & 43 & 41 \\
\hline Ela & 40 & 17 & 35 & 28 & 19 & 25 & 13 \\
\hline Chauk & 38 & 43 & 44 & 30 & 47 & 82 & 33 \\
\hline Minbu & 60 & 19 & 15 & 37 & 8 & 15 & 62 \\
\hline Magway & 51 & 39 & 25 & 24 & 18 & 39 & 54 \\
\hline Aunglan & 34 & 26 & 3 & 16 & 24 & 12 & 47 \\
\hline Pakokku & 35 & 43 & 35 & 36 & 57 & 92 & 48 \\
\hline Taundwingyi & 17 & 19 & 23 & 18 & 26 & 26 & 38 \\
\hline Gangaw & 35 & 26 & 38 & 21 & 42 & 22 & 25 \\
\hline Pauk & 23 & 25 & 38 & 38 & 41 & 59 & 28 \\
\hline Sinphyugyun & 31 & 75 & 66 & 56 & 60 & 75 & 48 \\
\hline Maungdaw & 137 & 125 & 113 & 103 & 261 & 105 & 111 \\
\hline Kyauktaw & 219 & 230 & 219 & 117 & 212 & 123 & 143 \\
\hline Sittwe & 88 & 65 & 87 & 70 & 125 & 312 & 190 \\
\hline Kyaukpyu & 235 & 48 & 80 & 159 & 125 & 38 & 148 \\
\hline Sandoway & 53 & 58 & 27 & 100 & 120 & 55 & 83 \\
\hline Gwa & 222 & 14 & 14 & 24 & 22 & 3 & 25 \\
\hline Ann & 227 & 114 & 118 & 237 & 137 & 96 & 163 \\
\hline
\end{tabular}


TABLE 3: Continued.

\begin{tabular}{|c|c|c|c|c|c|c|c|}
\hline Stations & OBS & PLIN-MYJ & Ferrier-MYJ & WSM6-MYJ & PLIN-YSU & Ferrier-YSU & WSM6-YSU \\
\hline Taungkok & 130 & 99 & 21 & 70 & 60 & 23 & 168 \\
\hline Myuaku & 79 & 110 & 214 & 64 & 196 & 40 & 89 \\
\hline Manaung & 160 & 46 & 25 & 65 & 103 & 64 & 130 \\
\hline Pyay & 39 & 12 & 2 & 18 & 14 & 5 & 67 \\
\hline Toungoo & 39 & 34 & 37 & 24 & 27 & 40 & 43 \\
\hline Zaungtu & 62 & 171 & 70 & 77 & 84 & 59 & 58 \\
\hline Bago & 54 & 43 & 44 & 42 & 114 & 83 & 86 \\
\hline Shwegyin & 70 & 30 & 142 & 32 & 39 & 77 & 66 \\
\hline Tharrawady & 98 & 56 & 30 & 34 & 65 & 13 & 42 \\
\hline Nyaunglaybin & 63 & 38 & 46 & 30 & 72 & 37 & 58 \\
\hline Kyopinkauk & 90 & 35 & 23 & 50 & 35 & 7 & 33 \\
\hline Taunggu (Air) & 37 & 46 & 35 & 25 & 29 & 36 & 40 \\
\hline Hmawbi & 94 & 50 & 53 & 26 & 60 & 55 & 62 \\
\hline Mingaladon & 88 & 30 & 14 & 75 & 86 & 21 & 59 \\
\hline Kabaaye & 95 & 61 & 14 & 117 & 170 & 27 & 124 \\
\hline C-Yangon & 131 & 78 & 13 & 69 & 144 & 15 & 74 \\
\hline Khayan & 85 & 39 & 47 & 24 & 29 & 22 & 1 \\
\hline Henzada & 138 & 51 & 17 & 29 & 20 & 8 & 17 \\
\hline Maubin & 83 & 28 & 14 & 41 & 61 & 19 & 17 \\
\hline Phyarpon & 113 & 29 & 40 & 2 & 29 & 22 & 12 \\
\hline Pathein & 85 & 39 & 19 & 20 & 23 & 31 & 11 \\
\hline Myaungmya & 50 & 11 & 40 & 8 & 21 & 25 & 16 \\
\hline Ngathyinegyaung & 138 & 29 & 6 & 28 & 32 & 12 & 26 \\
\hline Zalun & 136 & 33 & 19 & 32 & 16 & 20 & 13 \\
\hline Loikaw & 11 & 19 & 39 & 26 & 34 & 27 & 41 \\
\hline Hpa-An & 84 & 46 & 56 & 56 & 98 & 64 & 98 \\
\hline Thaton & 148 & 151 & 88 & 80 & 81 & 42 & 58 \\
\hline Mawlamyine & 75 & 71 & 70 & 73 & 159 & 107 & 74 \\
\hline Yay & 216 & 22 & 50 & 70 & 119 & 79 & 67 \\
\hline Mudon & 55 & 47 & 105 & 44 & 142 & 50 & 49 \\
\hline Kyaikkami & 73 & 86 & 55 & 23 & 50 & 22 & 50 \\
\hline Belin & 105 & 44 & 53 & 26 & 33 & 50 & 56 \\
\hline Theinzayet & 94 & 89 & 95 & 55 & 94 & 150 & 40 \\
\hline Dawei & 142 & 114 & 45 & 71 & 28 & 44 & 77 \\
\hline Myeik & 59 & 13 & 47 & 11 & 27 & 8 & 15 \\
\hline Kawthaung & 63 & 8 & 56 & 25 & 9 & 50 & 14 \\
\hline Launglon & 132 & 122 & 22 & 102 & 59 & 51 & 71 \\
\hline CocoIsland & 25 & 39 & 17 & 44 & 67 & 27 & 51 \\
\hline
\end{tabular}

The BS histogram shows the highest bias in light precipitation $(1-40 \mathrm{~mm})$ and the lowest bias in heavy precipitation (160-180 mm) (Figure 6(b)). The smallest errors are obtained for the large amounts of precipitation showing the good model skill in accurately predicting high precipitation intensity. The best combination of MP and PBL schemes varied with precipitation threshold; the verification results of the ETS histogram indicate that model configurations using WSM6-MYJ schemes better simulate high precipitation intensity (180-220 mm) (Figure 6(c)).

4.2. Sensitivity Experiments of Terrain. Based on the outcome of the combination of physical parameterization schemes and initial condition, WSM6-MYJ scheme is used for prediction of the ROANU's track and rainfall with three sensitivity experiments such as Without Rakhine Mountain (WoRM), with Half of Rakhine Mountain (HRM), and with Normal Rakhine Mountain (NRM) is performed. These experiments aim to examine the sensitivity of rainfall to track forecasting with artificially removed, reduced, and normal height of the Rakhine Mountain in the simulation of WoRM, HRM, and NRM.

The tracks of WoRM, HRM, and NRM are shown in Figure 7. All experiments successfully simulated the period from 24-h before landfall to 24-h after landfall in Bangladesh. The significant track errors within $70 \mathrm{~km}$ of the observed 
TABLE 4: The validation results show the combination of the different schemes generated the precipitation with the observed ones.

\begin{tabular}{lc}
\hline Combination of the schemes & RMSE \\
\hline LIN-MYJ & 55 \\
Ferrier-MYJ & 62 \\
WSM6-MYJ & 51 \\
LIN-YSU & 55 \\
Ferrier-YSU & 68 \\
WSM6-YSU & 53 \\
\hline
\end{tabular}

TABLE 5: The categorical verification scores of WSM6-MYJ scheme generated the threshold range $(\mathrm{mm})$ with the observed ones.

\begin{tabular}{lcc}
\hline Threshold range $(\mathrm{mm})$ & BIAS & ETS \\
\hline $1-20$ & 1.0 & 0.00 \\
$20-40$ & 1.0 & 0.06 \\
$40-60$ & 0.7 & 0.13 \\
$60-80$ & 0.5 & 0.24 \\
$80-100$ & 0.5 & 0.18 \\
$100-120$ & 0.6 & 0.21 \\
$120-140$ & 0.3 & 0.11 \\
$140-160$ & 0.3 & 0.16 \\
$160-180$ & 0.3 & 0.23 \\
$180-200$ & 0.3 & 0.32 \\
$200-220$ & 0.3 & 0.32 \\
\hline
\end{tabular}

location are found in all three experiments, which made landfall in Bangladesh. Both WoRM and HRM experiments have approximately the same track as JTWC but turns obviously northwestward and southeastward compared to JTWC before the second landfall position (Figure 7(a)). The track of HRM missed first landfall and moved more southward than JTWC and thereafter turns northward before the second landfall position, resulting in that the TC track may be varied by the cyclone-Rakhine Mountain interaction. Except for NRM, all the forecasted tracks moved northward. The track of NRM is able to capture the second landfall position and downgrade in Myanmar. The NRM captures the second landfall position. It is pointed out that the presence of Rakhine Mountain leads to discontinuing track. Low bias is found at the initial time and high bias is found after the landfall (Figure 7(b)). All three experiments forecasted the observed tropical cyclone intensity reasonably well in terms of minimum sea level pressure and maximum surface wind (Figures $7(\mathrm{c})$ and $7(\mathrm{~d})$ ).

In the first sets of experiment in WoRM, the total 48$\mathrm{h}$ accumulated rainfall for the whole country is $4720 \mathrm{~mm}$, which is lower than observed $6826 \mathrm{~mm}$ (Figure 8). The heaviest rainfall area is located in the northwestern part of Myanmar, which is the same with actual second landfall position but extends more to the northeastern region (Figure 9(a)). WoRM experiments overestimated the peak rainfall with maximum values of $276 \mathrm{~mm}$ compared to the observed $254 \mathrm{~mm}$ of DMH. The simulated rainfall forecast in second experiment of HRM is $4921 \mathrm{~mm}$, which is larger than WoRM (Figure 8). The maximum rainfall area extends more to the southwest (Figure 9(b)) and the peak value is $293 \mathrm{~mm}$, which is larger than WoRM. In the last experiment in NRM, the simulated rainfall is $4667 \mathrm{~mm}$, which is the lowest in all three experiments (Figure 8). However, the maximum rainfall area in northeastern region is narrower than WoRM and HRM and extends to the southwestern region (Figure 9(c)). Its peak value is $237 \mathrm{~mm}$, which is smaller than other two experiments and nearly close to the observed value (Figure 8). By analyzing the scatter plots of the observed rainfall versus NRM, HRM, and WoRM experiments, it showed that the correlations are as high as $0.62,0.52$, and 0.41 , respectively (Figure 10). The results of the analysis showed that even with removed or reduced height of the Rakhine Mountain, the track moved northwestward and rainfall amount was larger than NRM. Even though NRM experiment track was very close to the observed track, the total rainfall amount could not yield the observed amounts. However, the NRM experiment has the highest correlation with the observed rainfall and the maximum rainfall amount could capture the observed amounts.

4.3. Sensitivity to Planetary Boundary Layer Schemes. In the second set of experiments, the PBL schemes of MYJ and YSU are selected with the combination of LIN, Ferrier, and WSM6 schemes. The track positions of the simulated cyclone from experiments with different PBL schemes along with JTWC observations are shown in Figures 3(a) and 4(a). From the results of the average track errors, it is noted that the 48-h track error of ROANU with MYJ was $60 \mathrm{~km}$, which was lower than the experiment using YSU as the PBL scheme (Figures 3(b) and 4(b)). Thus for the overall performance of track and intensity, the MYJ scheme is found to be better than the experiment with the YSU scheme. It is revealed by $[8,43]$ that the $48 \mathrm{~h}$ track error of Nargis with MYJ as PBL scheme was $252 \mathrm{~km}$, which was slightly higher and Orissa super cyclone was $25 \mathrm{~km}$ which was lower than that of this study. The $48 \mathrm{~h}$ track error of [44] investigated the sensitivity of different PBL schemes at Kalpakkam (a tropical site) and verified that YSU scheme simulated various PBL quantities which are in better agreement with the observations. The present study of PBL in MYJ scheme is better than YSU. The simulated minimum central sea level pressure (CSLP) and the maximum surface winds at every $6 \mathrm{~h}$ interval are shown in Figures 3 and 4 . It is noted that the intensity of the simulated storm is overpredicted in all the cases as seen from the time series of the CSLP values. The deepening period was about 24 hours in all the cases. The experiments with LIN scheme produced the strongest cyclone with a CSLP of $960 \mathrm{hPa}$ while Ferrier and WSM6 schemes produced $970 \mathrm{hPa}$ (Figures 3(c) and 4(c)). The mature stage of the storm was about 18 hours for all the schemes. The observed lowest CSLP of the storm was $983 \mathrm{hPa}$ attained at the 30 hours (06 UTC on 21 May 2016). The lowest CSLP in all the six experiments was attained about 06 hours later than the observations. The maximum wind speed simulated in different cases varies from 28 to $37 \mathrm{~ms}^{-1}$. The experiment with the LIN scheme shows a maximum wind speed about $37 \mathrm{~ms}^{-1}$, while the experiment with the Ferrier scheme shows $32 \mathrm{~ms}^{-1}$ in PBL scheme of MYJ and YSU. Experiments with the WSM6 scheme show a maximum wind speed about $37 \mathrm{~ms}^{-1}$ and $32 \mathrm{~ms}^{-1}$ in PBL scheme of 


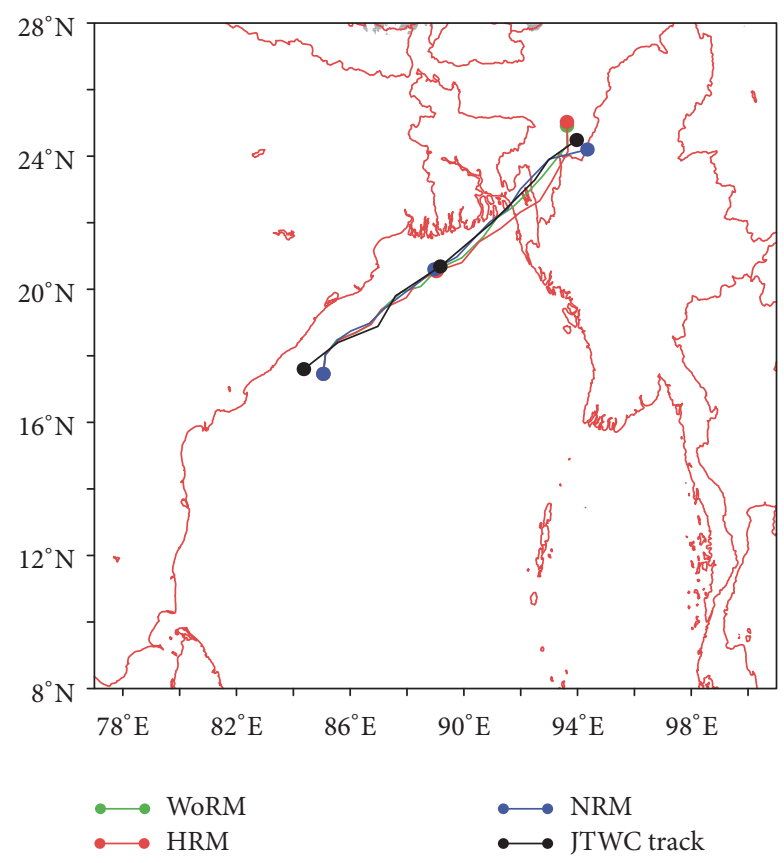

(a)

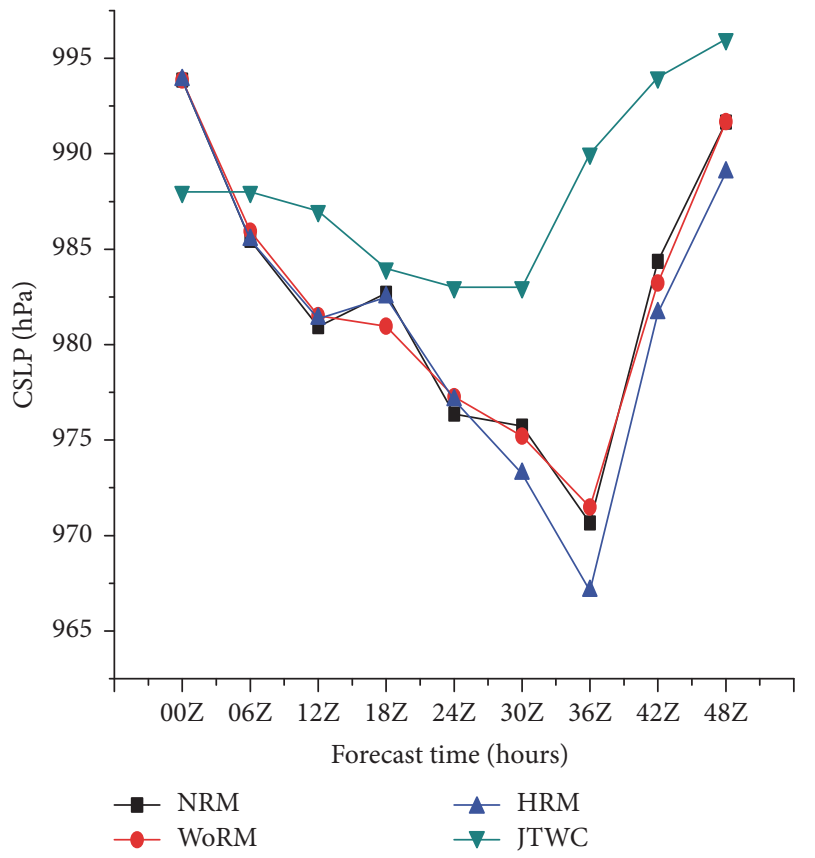

(c)

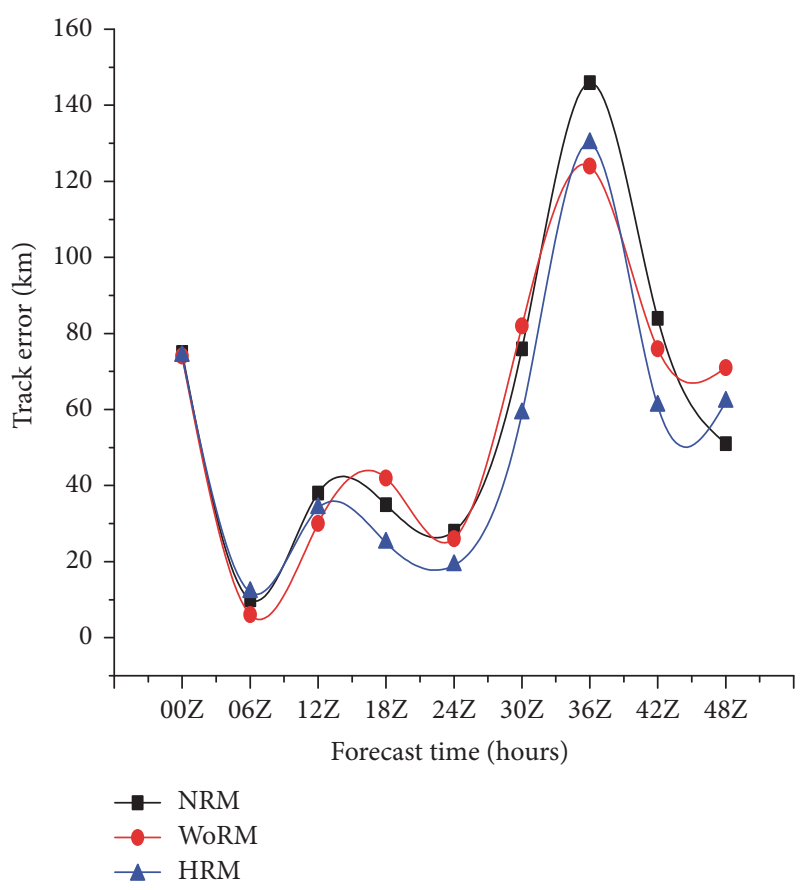

(b)

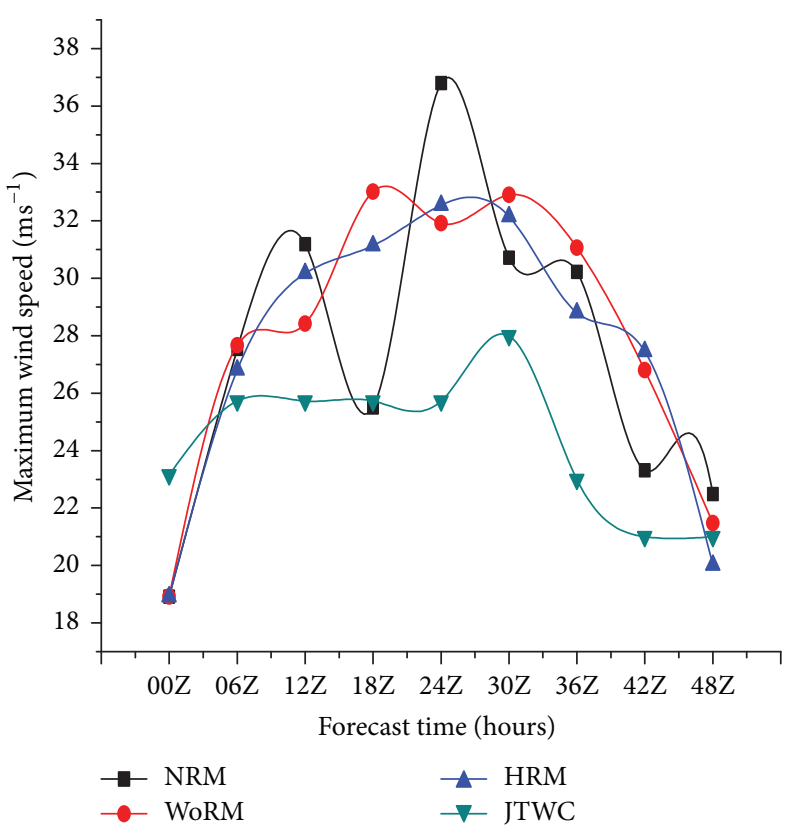

(d)

Figure 7: The 48-h forecasted (a) track, (b) track error (km), (c) Central Sea Level Pressure (hPa) (CSLP), and (d) maximum wind speed $\left(\mathrm{ms}^{-1}\right.$ ) for Without Rakhine Mountain (WoRM), Half Rakhine Mountain (HRM), and Normal Rakhine Mountain (NRM) experiments.

MYJ and YSU, respectively (Figures 3(d) and 4(d)). All the experiments obtain overpredictions compared to the JTWC observation of $28 \mathrm{~ms}^{-1}$. The maximum winds associated with the storm are weakened gradually in all the experiments. Thus the MYJ scheme shows stronger TC intensity in terms of maximum winds and CSLP than YSU scheme did.
The comparison of the observed $48 \mathrm{~h}$ accumulated rainfall for 21 May and 22 May 2016 in the 91 available stations (Figure 11(a)) with the 3 -km grid results from the different model configurations is presented in Figures 11(b)-11(g). The simulation with WSM6- MYJ scheme shows large precipitation amounts in the northwest and southwest of Myanmar, 


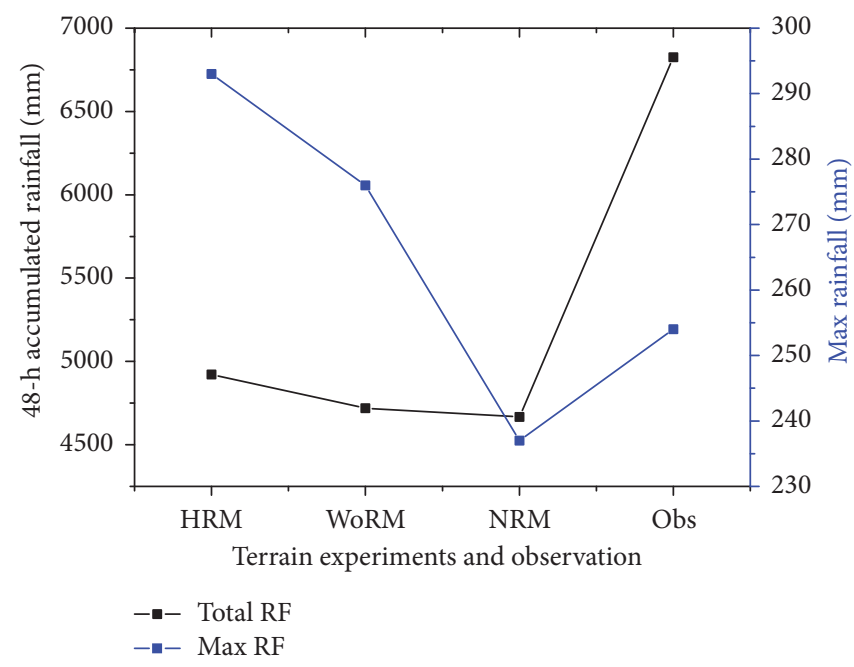

FIGURE 8: The total accumulated rainfall (mm) from 0000 UTC 20 May to 0000 UTC 22 May (black line) and maximum rainfall (mm) (blue line) for the whole country from observations (Obs), Half Rakhine Mountain (HRM), Without Rakhine Mountain (WoRM), and Normal Rakhine Mountain (NRM) simulations.
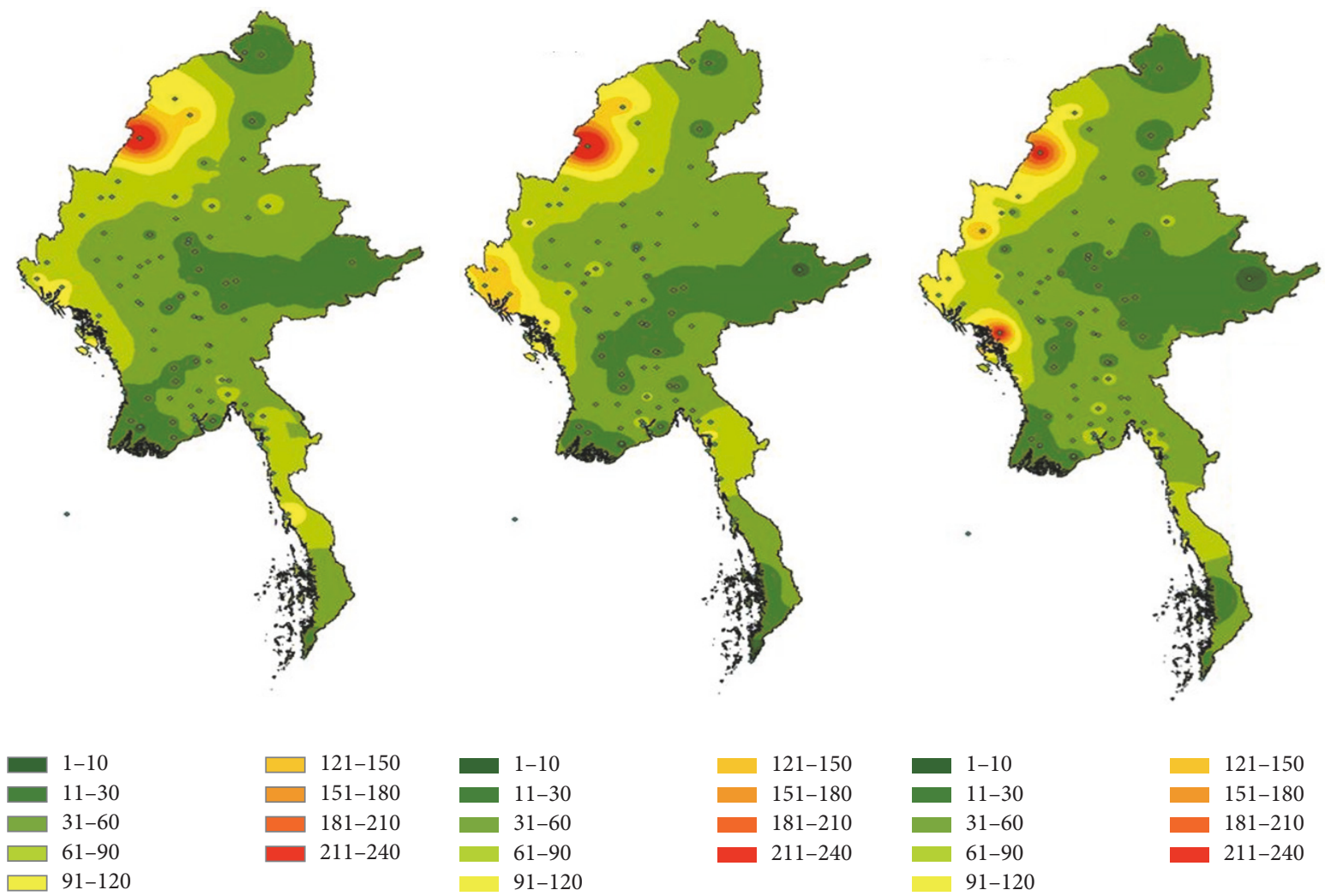

(a) WoRM

(b) HRM

(c) NRM

FIGURE 9: 48-h accumulated rainfall (mm) from 0000 UTC 21 May to 0000 UTC 22 May for (a) Without Rakhine Mountain (WoRM), (b) with Half of Rakhine Mountain (HRM), and (c) with Normal Rakhine Mountain for tropical cyclone ROANU.

where the heaviest rainfall occurred with maximum values 230, 157, and $237 \mathrm{~mm}$ (Figure 11(d)) for $48 \mathrm{~h}$ agreeing with the DMH observations of 254, 88, and $227 \mathrm{~mm}$ at Homalin, Hakha, and Ann, respectively (Table 3). The simulation of LIN-MYJ scheme which produced the maximum values was less than other schemes, which is in agreement with its strongest cyclone intensity (Figure 11(b)). It may be related to the second landfall of the cyclone. Ferrier-MYJ scheme produced the maximum value exceeding about $20 \mathrm{~mm}$ compared to observations over northwest of Myanmar and reducing 


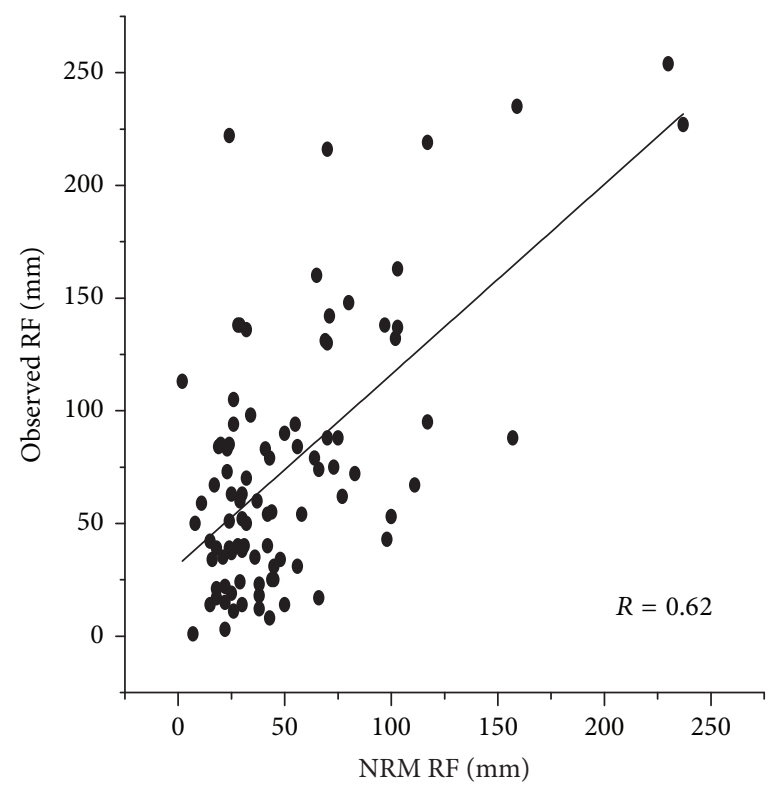

(a)

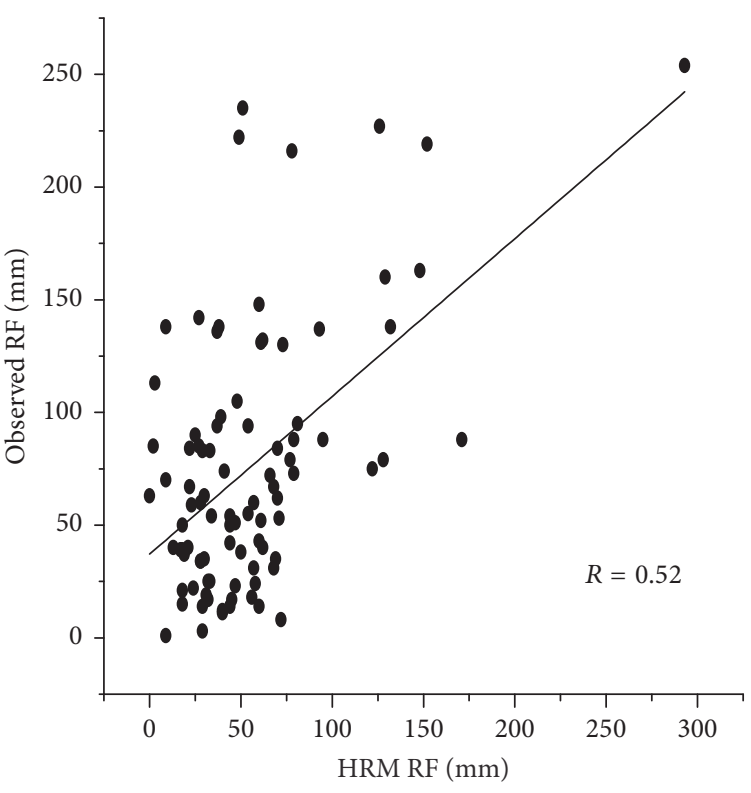

(b)

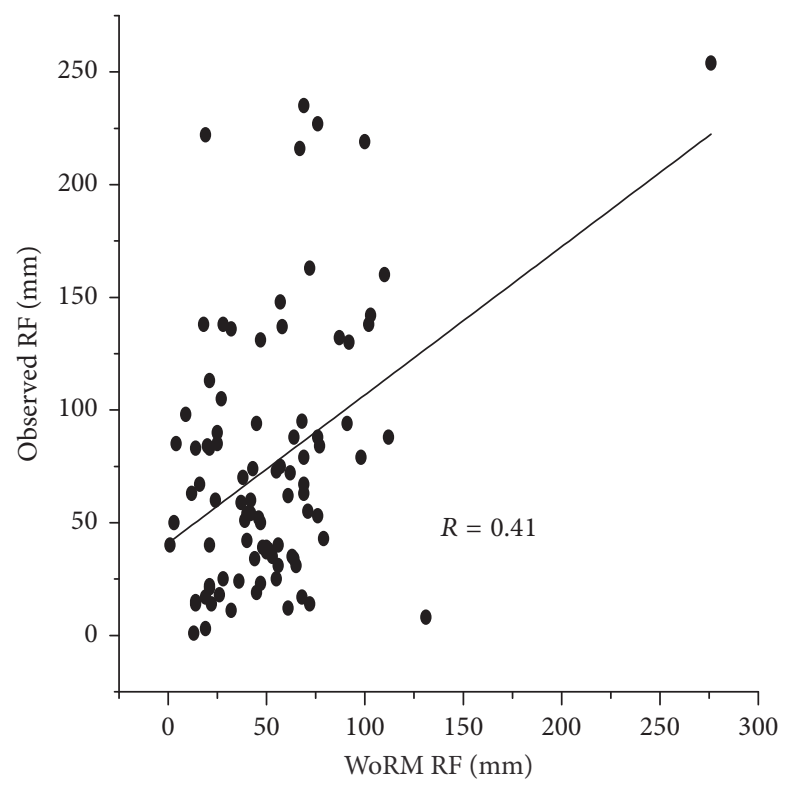

(c)

FIGURE 10: Scatter plots of 48-h accumulated grid point rainfall from NRM, HRM, and WoRM simulations versus observation stations rainfall.

about $100 \mathrm{~mm}$ compared to observations over southwest of Myanmar (Figure 11(c)). LIN-YSU scheme generated the maximum value exceeding above $50 \mathrm{~mm}$ at Hakha (northwest of Myanmar) and above $100 \mathrm{~mm}$ at Maungdaw (southwest of Myanmar) (Figure 11(e)). It was consistent with its simulated cyclone intensity and second landfall point. Ferrier and WSM6 with YSU scheme produced the heavy precipitation value reducing below $50 \mathrm{~mm}$ over northwestern and below $100 \mathrm{~mm}$ over southwestern regions compared to observations (Figures 11(f) and 11(g)). WSM6 scheme produced the intensity and distribution of precipitation amount which is the closest to the observations. In accordance with the above results, the location of the precipitation maxima and the track of the cyclone simulated by WSM6-MYJ are in good agreement with observations although it does underestimate the southern part of Myanmar.

Figure 12 shows the east-west cross sections of horizontal wind speed, for TC ROANU. In this section, east-west cross sections of horizontal wind speed and vertical velocity are analyzed to understand which scheme performs better inner core structure of TC. All the combinations succeed in simulating the region of maximum winds and strong westerlies at $200 \mathrm{hPa}$ level on the eastern side of the cyclone center. The horizontal wind speeds of $40 \mathrm{~ms}^{-1}$ are found in LIN-MYJ (Figure 12(a)) and of $35 \mathrm{~ms}^{-1}$ are seen in Ferrier-MYJ and WSM6-MYJ (Figures 12(b) and 12(c)). The horizontal wind 

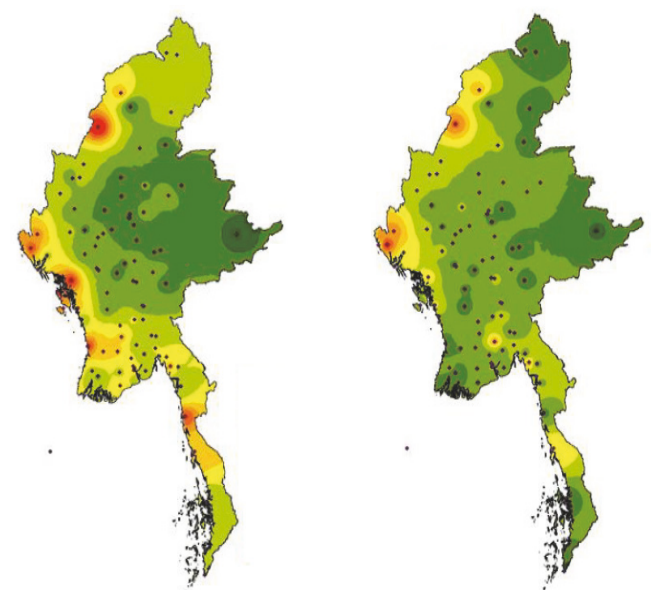

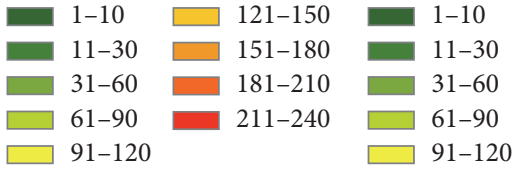

(a)

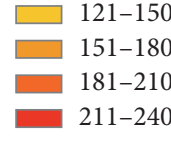

(b)
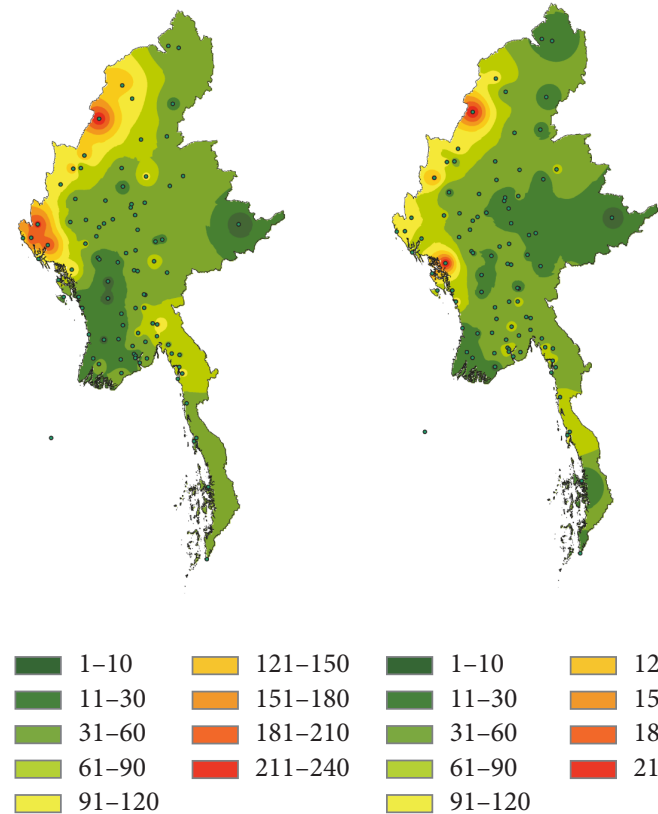

(c)

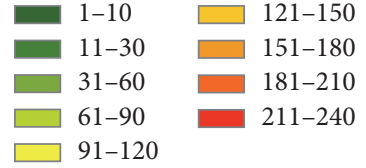

(d)
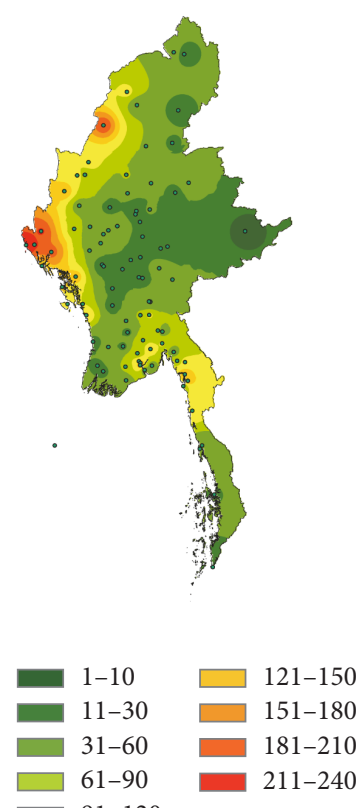

(e)
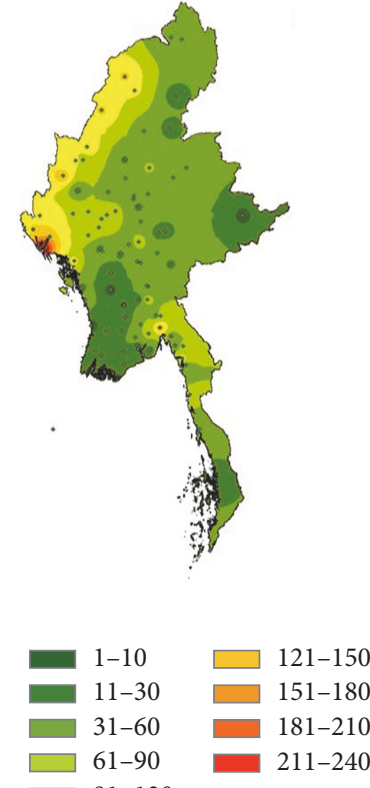

(f)
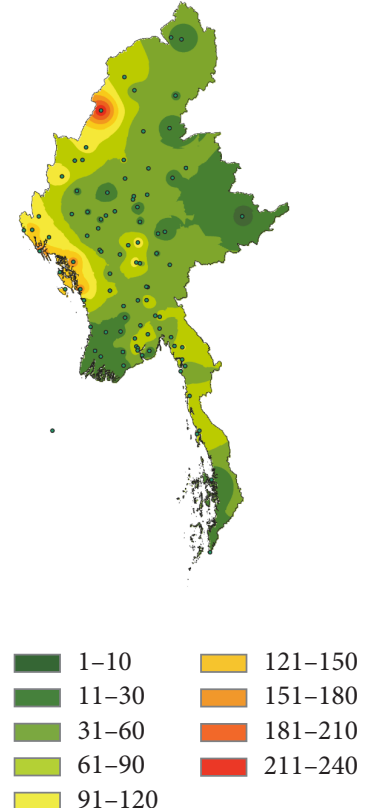

(g)

FIgURE 11: $48 \mathrm{~h}$ accumulated precipitation (mm) from 0000 UTC 21 May to 0000 UTC 22 May for (a) observations, (b) LIN-MYJ, (c) FerrierMYJ, (d) WSM6-MYJ, (e) LIN-YSU, (f) Ferrier-YSU, and (g) WSM6-YSU for tropical cyclone ROANU.

speeds of $25-30 \mathrm{~ms}^{-1}$ are seen in YSU as PBL scheme (Figures 12(d)-12(f)). This can be clearly seen that MYJ experiment has strong horizontal wind speed of $35-40 \mathrm{~ms}^{-1}$ extending from the surface to $200 \mathrm{hPa}$. Moreover MYJ scheme simulates stronger TCs than YSU. The combination of WSM6-MYJ scheme can well simulate the structure on both sides with the region of maximum wind speed $30 \mathrm{~ms}^{-1}$ of the cyclone center.

Figure 13 shows the east-west cross section of vertical velocity in $\mathrm{ms}^{-1}$ and negative values or shades represented downdraft regions. The PBL scheme in MYJ generates intense storms with strong updrafts $4-5 \mathrm{~ms}^{-1}$ at mid-levels. From Figures 13(a)-13(c), it is also clear that at all vertical levels the intense updrafts are confined to a very narrow strip and weak updrafts spread horizontally on both sides of the center in MYJ experiments. Moreover, the concentration of updrafts prevails on both sides of the center of the TC leading to maximum convection and hence rainfall over the region. The strong updrafts $2-4 \mathrm{~ms}^{-1}$ at mid-levels are found in 


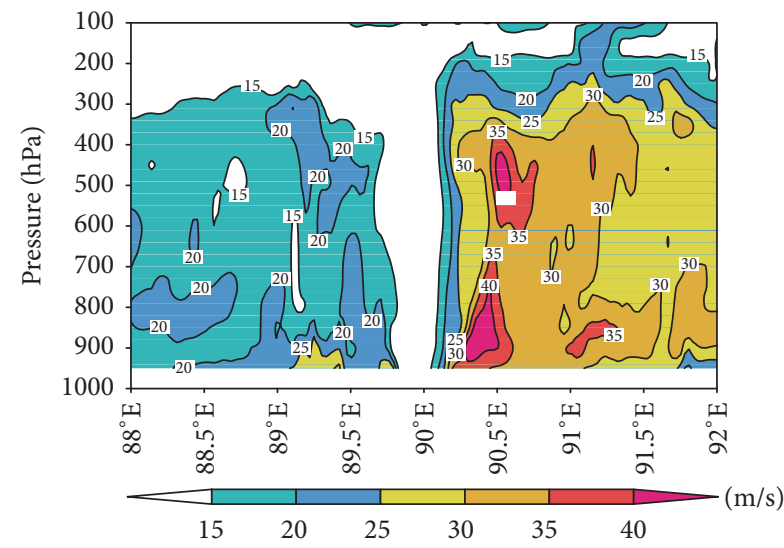

(a)

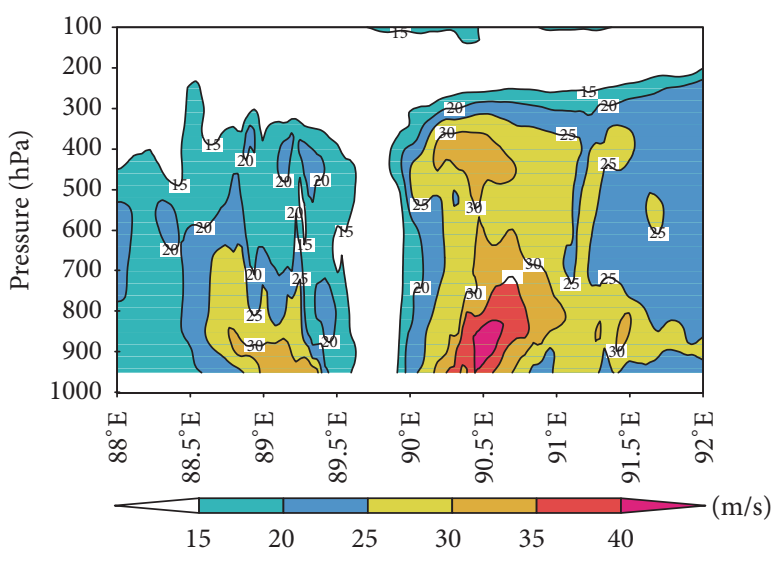

(c)

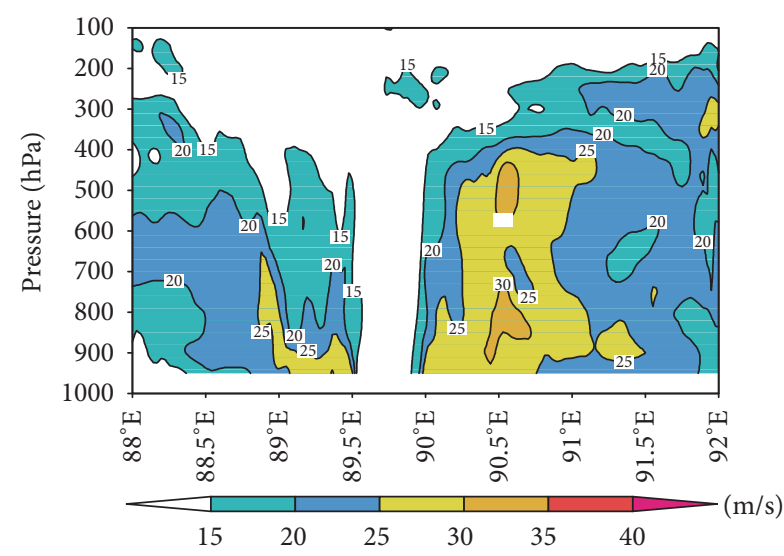

(e)

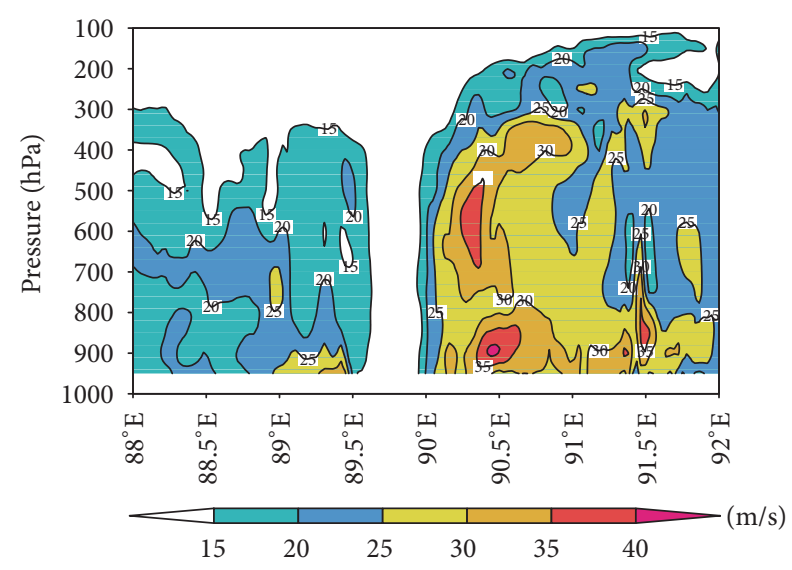

(b)

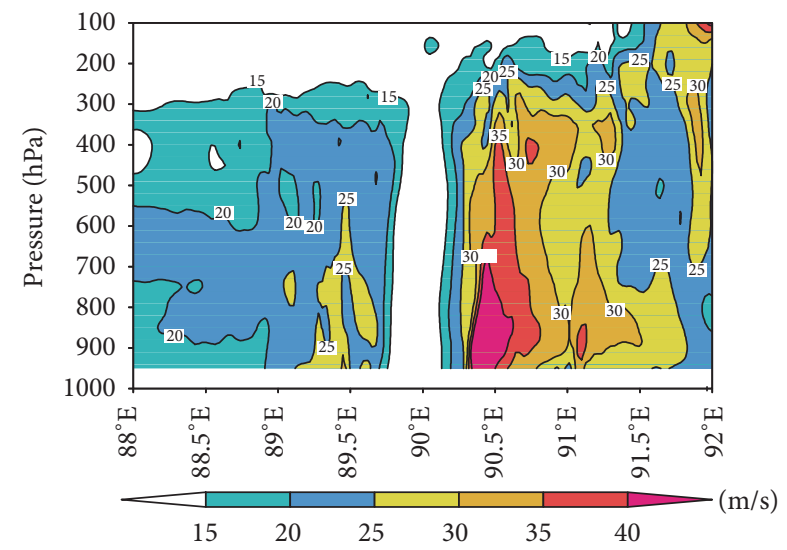

(d)

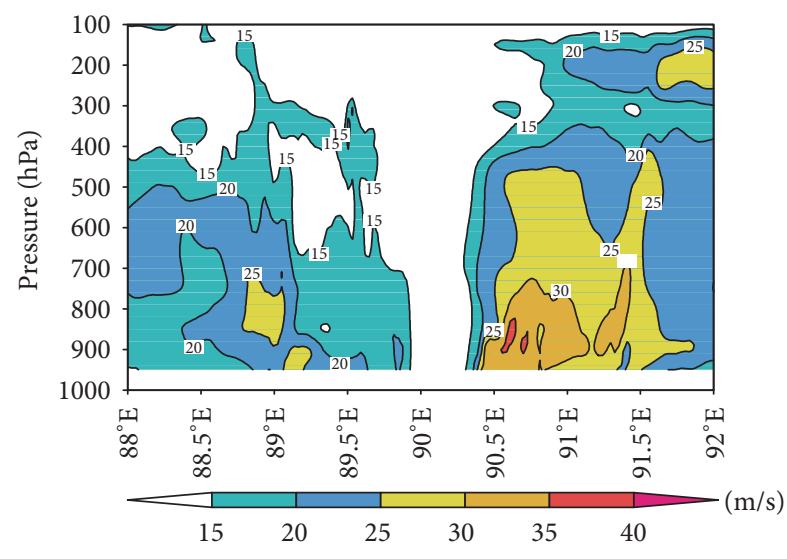

(f)

FIGURE 12: East-west cross section of horizontal wind speed $\left(\mathrm{ms}^{-1}\right)$ through the center of TC ROANU from different combination experiments (a) LIN-MYJ, (b) Ferrier-MYJ, (c) WSM6-MYJ, (d) LIN-YSU, (e) Ferrier-YSU, and (f) WSM6-YSU ( $>15 \mathrm{~ms}^{-1}$ is shaded).

eastern side of the cyclone in YSU as PBL scheme (Figures 13(d)-13(f)). This enhancement of large scale upward motions in MYJ experiment in and around the center of the TC helps the arrival of sensible and latent heat from the boundary layer to the center of the TC and helps in TC strengthening. The improved updrafts and storm intensification rate can be recognized in the reaction mechanism between low-level convergence of warm air, latent heat release in the cyclone center, and reducing the surface pressure in the inner core of the storm [45].

4.4. The Orographic Effect of Rakhine Mountain. To reveal a reason for the height of the Rakhine Mountain related to rainfall amount, the differences in vertically integrated moisture flux between the NRM and HRM, and the HRM and WoRM are shown in Figure 14. It compares the location where 


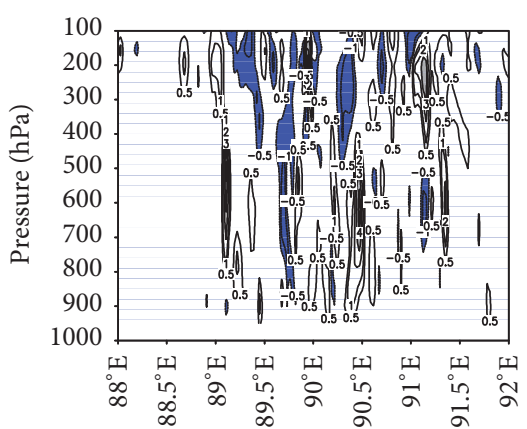

(a) LIN-MYJ

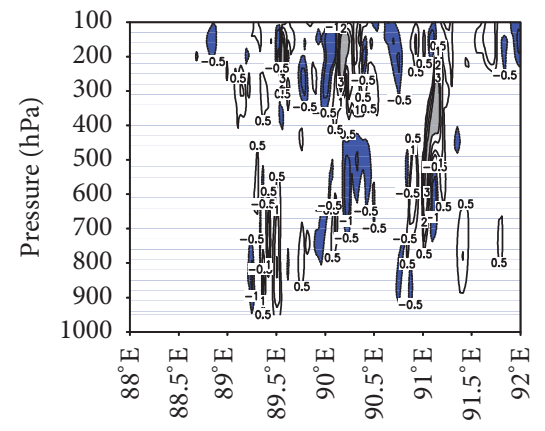

(d) LIN-YSU

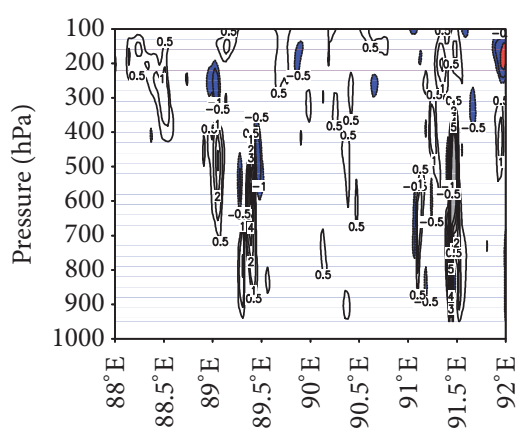

(b) Ferrier-MYJ

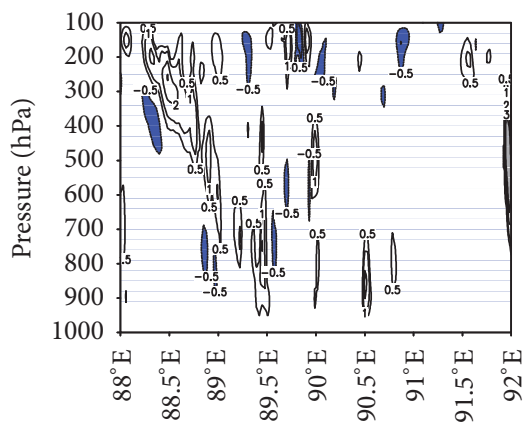

(e) Ferrier-YSU

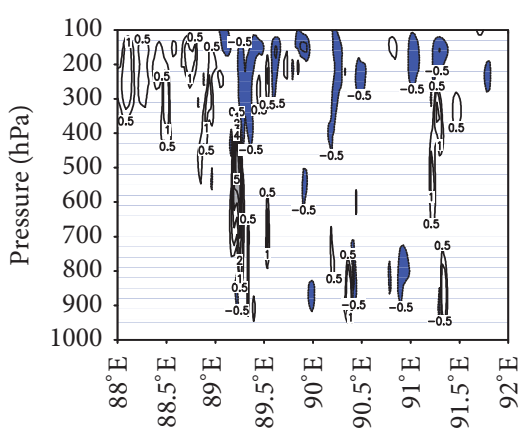

(c) WSM6-MYI

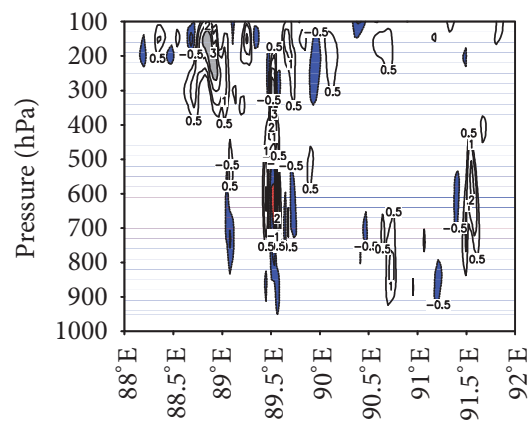

(f) WSM6-YSU

FIGURE 13: Same as Figure 12 but for vertical velocity $\left(\mathrm{ms}^{-1}\right)$ (negative values are shaded).

the strongest rainfall occurred at 1800 UTC 21 May in terrain experiments. There were positive peaks of moisture flux from the cyclone that moved eastward and northward moisture flux from the Bay of Bengal and Andaman Sea to the western Myanmar. The moisture flux was not directly advected to the positive peak but was propagated northward along the Rakhine Mountain. This indicated that the direction of horizontal moisture flux (wind) forced the convergence. Comparing Figures 14(a) and 14(b), the positive moisture flux peak in Figure 14(b) and rainfall in Figure 15(a) over mountain were eliminated, which means that the rainfall was caused by a mountain. It is clear that, with the reduction of the mountain height, the positive peak of water vapor converged at the northern part of the mountain.

Figures 15(a), 15(b), and 15(c) show the distribution of rainfall in WoRM, HRM, and NRM experiments and how the orographic effect significantly influences rainfall during TC events. The reduction of rainfall along the Rakhine Mountain range was shifted northward in WoRM experiment (Figure 15(a)). It is supposed that these shifts in rainfall patterns are due to the movement of the TC when the TC does not experience friction due to the Rakhin Mountain. Thus, nonorographic effect forced the rainfall in this region. An increase in rainfall was observed in the leeward side of the Rakhine Mountain as in the experiments of HRM and NRM (Figures 15(b) and 15(c)), in which rainfall that has been distributed by the orographic effect along the Rakhine Mountain has shifted towards the mountain ranges. It is found that, in the absence of the Rakhine Mountain, the maximum rainfall amount is shifted to the north of the Mountain. In HRM and NRM, the maximum rainfall amount is observed at the leeward side of the mountain. References [46-48] revealed that the experiments with decreased terrain height or no topography produced reduced accumulated rainfall in the simulation of TC, which is consistent with the present study.

\section{Conclusions}

In this paper, the impacts of microphysics schemes and topography on the prediction of heavy rainfall in western Myanmar are examined through a case study of TC ROANU (2016) over Bay of Bengal. For this purpose, a total of six experiments were conducted with three microphysics schemes (LIN, Ferrier, and WSM6) and two PBL schemes (MYJ and YSU) by using WRF model at 3-km resolution. Further a total of three terrain experiments (WoRM, HRM, and NRM) are carried out by using this fit scheme and the salient results are summarized as follows.

(1) The impact of microphysics on storm intensity forecast is evident. The MP scheme LIN produced a storm with better intensity. We have shown that the intense storm such as LIN has produced more heating at the $300-100 \mathrm{hPa}$ layer compared to Ferrier and WSM6. We have explained two possible mechanisms responsible for this intensification of LIN storm. There are large amount of melting and evaporation processes from frozen hydrometeors and large amount of liquid hydrometeors. The quantitative amount of precipitation and distribution are well correlated to the latent heat release in the storm. The WSM6 scheme produced the storm close to the 


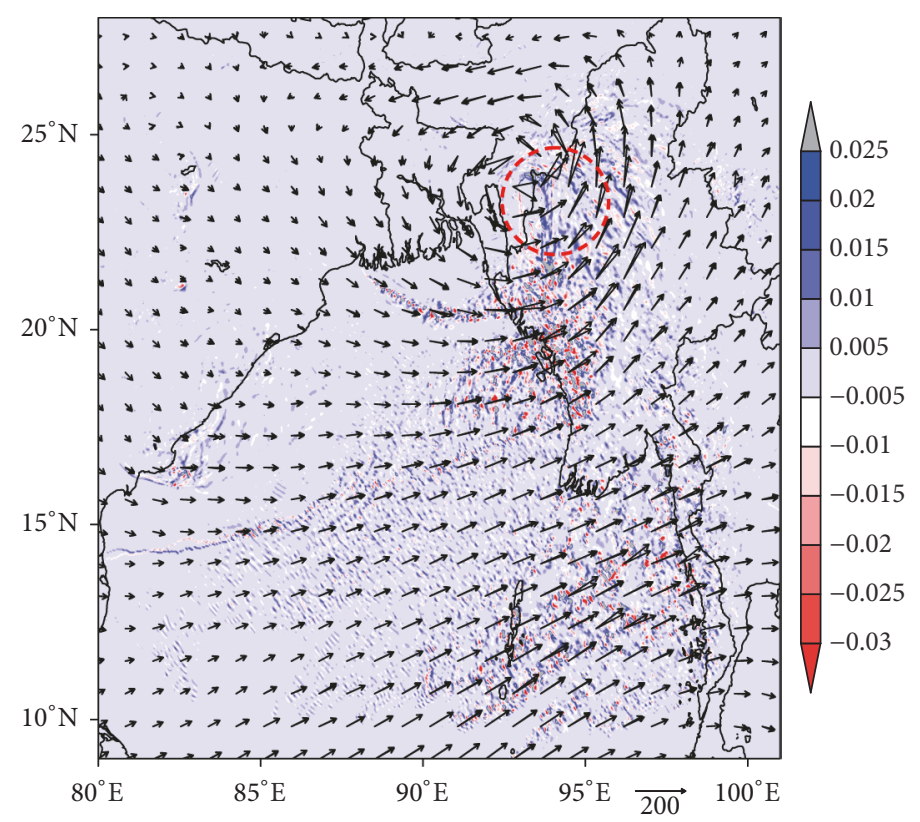

(a)

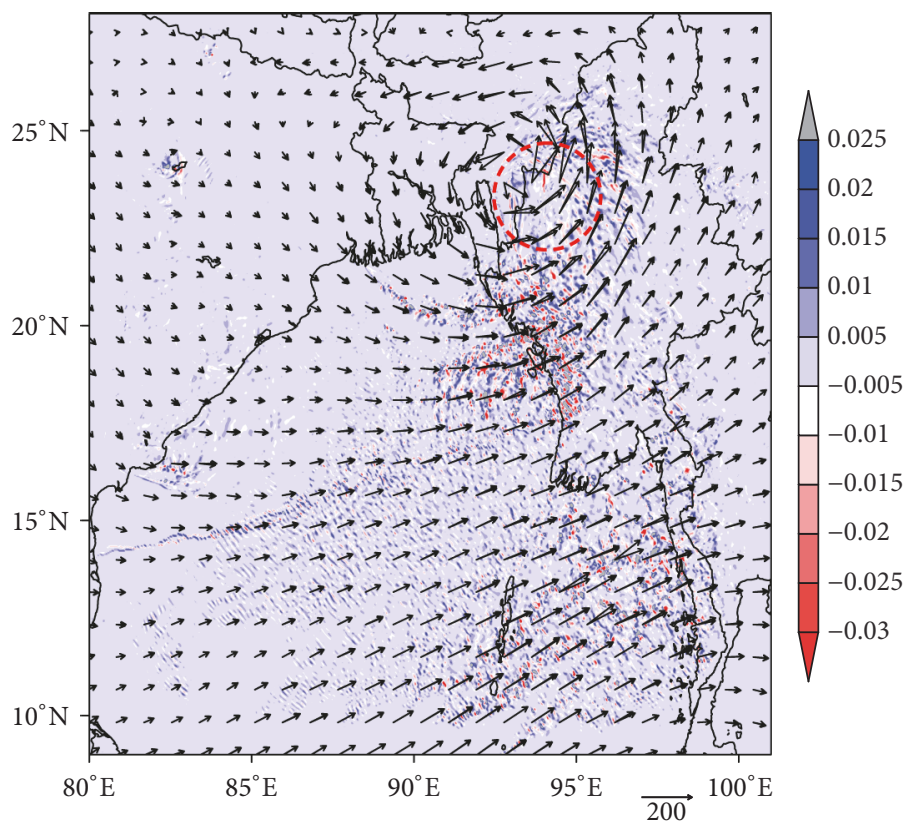

(b)

FIGURE 14: Vertically integrated (1000-300 hPa) moisture flux convergence (shaded) $\left(\mathrm{kg} \mathrm{m}^{-2} \mathrm{~s}^{-1}\right)$ and its flux $(\operatorname{arrow})\left(\mathrm{kg} \mathrm{m}^{-1} \mathrm{~s}^{-1}\right)$ of the 1800 UTC on 21 May 2016, (a) NRM-HRM and (b) HRM-WoRM.

observed JTWC estimates. The track error was found to be least for the WSM6 scheme.

(2) The track forecasting of PBL in MYJ scheme is well captured compared to YSU. In the track forecast of TC ROANU, the PBL scheme is sensitive compared to MP scheme. The combination of WSM6-MYJ has close resemblances with the observations.

(3) The WoRM and HRM experiments produced increased intensity and distribution of rainfall. The track moved in the northwest direction in the WoRM and HRM while the track moved into Myanmar in the presence of Rakhine Mountain during the premonsoon. Moreover, Rakhine Mountain is more sensitive to movement of the TC and spatial and distribution of heavy rainfall over western Myanmar.

(4) In the presence of Rakhine Mountain, the maximum rainfall patterns are found in the leeward side of the Mountain. In the absence of Rakhine Mountain, the 


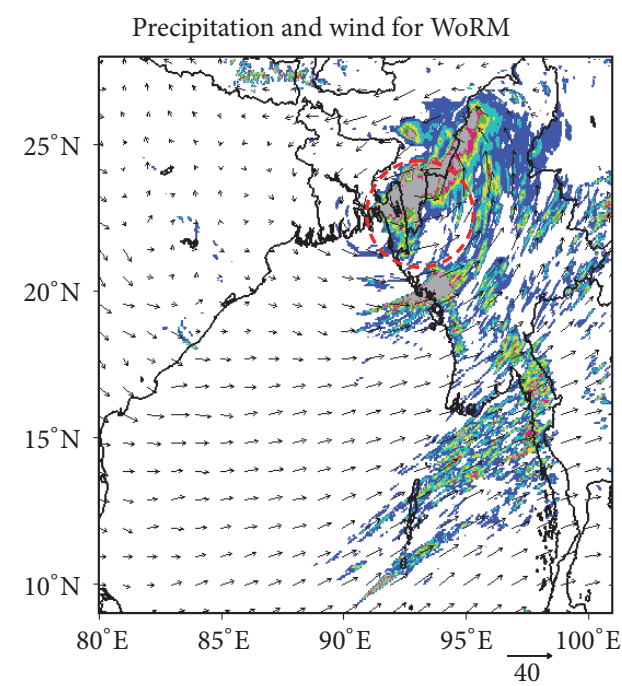

(a)

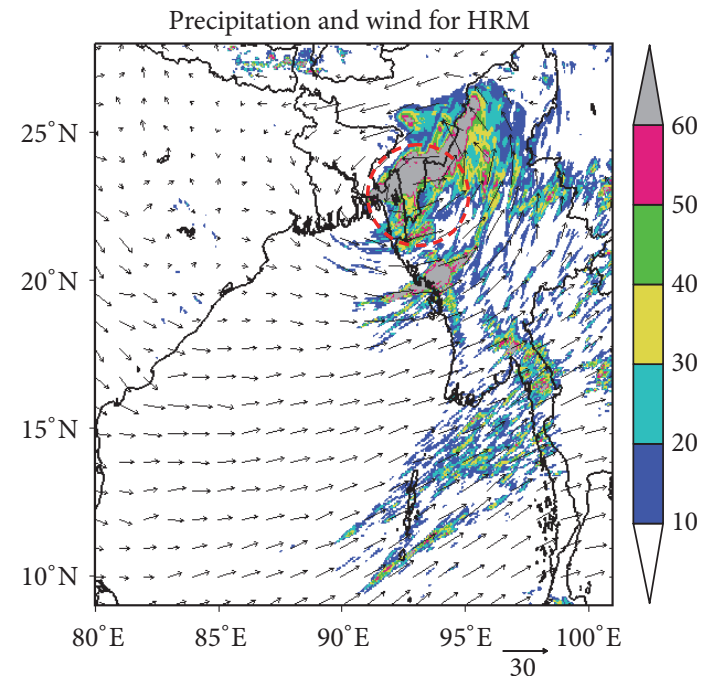

(b)

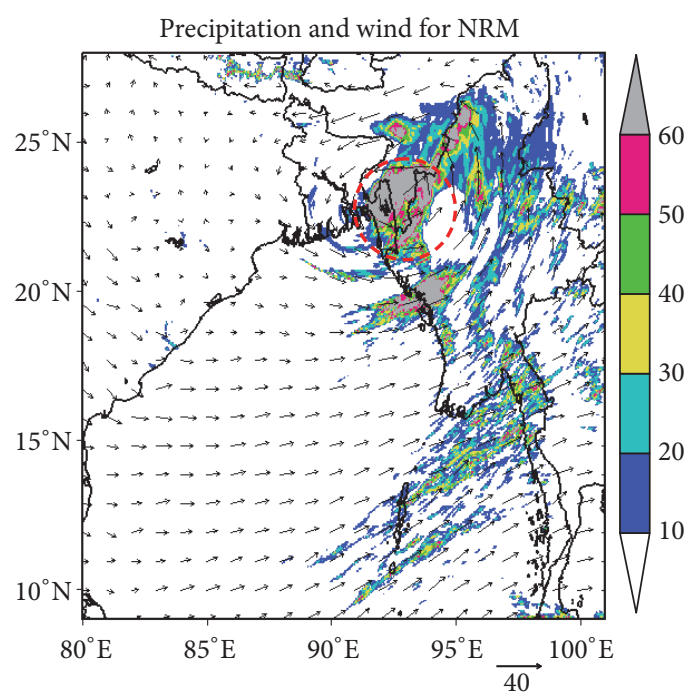

(c)

FIgURE 15: The spatial distribution of TC ROANU's rainfall over western Myanmar. The wind vector $\left(\mathrm{ms}^{-1}\right)$ at $850 \mathrm{hPa}^{2}$ and the simulated accumulated rainfall (unit: mm) from 0900 UTC 21 to 1800 UTC 21 May by (a) WoRM, (b) HRM, and (c) NRM.

maximum rainfall pattern shifted to the north of the mountain and reduced the rainfall amount.

The results from this study highlighted the impacts of microphysics and terrain experiments in tropical cyclone track, intensity, and rainfall prediction over western Myanmar. Although the moisture flux from the Bay of Bengal is necessary for heavy rainfall, orographic effects play an important role in fixing the rainfall region. This information combines with conventional prediction techniques to be a useful forecast aid to the TC forecaster. In the future, we would like to study the impact of assimilating data system on a landfalling hurricane using the WRF (Weather Research and Forecasting) hybrid ensemble three-dimensional variational (3DVar) (En3DVar) method to improve the forecasting hurricane track and intensity.

\section{Conflicts of Interest}

The authors declare that they have no conflicts of interest.

\section{Acknowledgments}

This research was primarily supported by the National Natural Science Foundation of China (41430427), the 973 Program (Grant no. 2013CB430102), the Natural Science Foundation of Jiangsu Province under Grant no. BK20160954, the Beijige Funding from Jiangsu Research Institute of Meteorological Science (Grant nos. BJG201510, BJG201604, and BJG201409), the Startup Foundation for Introducing Talent of NUIST (Grants 2016r27, 2014R007, and 2016r043), and the Priority Academic Program Development of Jiangsu Higher Education Institutions (PAPD). The first author also acknowledges Feifei Shen, Shizhang Wang, and Dongmei Xu for 
helpful discussions and assistance with the initial drafts. Supercomputers at SGI Altix3700 BX2, Nanjing University of Information Science \& Technology, were used.

\section{References}

[1] C. Neumann, "Global guide to tropical cyclone forecasting," Tech. Rep. 560, World Meteorological Organization, Geneva, Switzerland, 1993, WMO/TC, Report No. TCP-31.

[2] K. Hoarau, J. Bernard, and L. Chalonge, "Intense tropical cyclone activities in the northern Indian Ocean," International Journal of Climatology, vol. 32, no. 13, pp. 1935-1945, 2012.

[3] D. Shrestha, R. Deshar, and K. Nakamura, "Characteristics of summer precipitation around the western ghats and the Myanmar West Coast," International Journal of Atmospheric Sciences, vol. 2015, Article ID 206016, 10 pages, 2015.

[4] G. A. Efstathiou, N. M. Zoumakis, D. Melas, C. J. Lolis, and P. Kassomenos, "Sensitivity of WRF to boundary layer parameterizations in simulating a heavy rainfall event using different microphysical schemes. Effect on large-scale processes," Atmospheric Research, vol. 132-133, pp. 125-143, 2013.

[5] M. A. K. Mallik, M. N. Ahasan, and M. A. M. Chowdhury, "Simulation of Track and Landfall of Tropical Cyclone Viyaru and Its Associated Strom Surges Using NWP Models," The American Journal of the Medical Sciences, vol. 3, pp. 11-21, 2015.

[6] D. V. B. Rao and D. H. Prasad, "Sensitivity of tropical cyclone intensification to boundary layer and convective processes," Natural Hazards, vol. 41, no. 3, pp. 429-445, 2007.

[7] D. Srinivas and D. V. Bhaskar Rao, "Implications of vortex initialization and model spin-up in tropical cyclone prediction using Advanced Research Weather Research and Forecasting Model," Natural Hazards, vol. 73, no. 2, pp. 1043-1062, 2014.

[8] D. V. B. Rao and D. Srinivas, "Multi-Physics ensemble prediction of tropical cyclone movement over Bay of Bengal," Natural Hazards, vol. 70, no. 1, pp. 883-902, 2014.

[9] M. Deshpande, S. Pattnaik, and P. S. Salvekar, "Impact of physical parameterization schemes on numerical simulation of super cyclone Gonu," Natural Hazards, vol. 55, no. 2, pp. 211-231, 2010.

[10] Y. Wang, "An explicit simulation of tropical cyclones with a triply nested movable mesh primitive equation model: TCM3. Part II: Model refinements and sensitivity to cloud microphysics parameterization," Monthly Weather Review, vol. 130, no. 12, pp. 3022-3036, 2002.

[11] M. S. Deshpande, S. Pattnaik, and P. S. Salvekar, "Impact of cloud parameterization on the numerical simulation of a super cyclone," Annales Geophysicae, vol. 30, no. 5, pp. 775-795, 2012.

[12] C. V. Srinivas, R. Venkatesan, D. V. Bhaskar Rao, and D. Hari Prasad, "Numerical simulation of Andhra severe cyclone: model sensitivity to the boundary layer and convection parameterization," Pure and Applied Geophysics, vol. 164, no. 8-9, pp. 1465-1487, 2007.

[13] S. A. Braun and W.-K. Tao, "Sensitivity of high-resolution simulations of Hurricane Bob (1991) to planetary boundary layer parameterizations," Monthly Weather Review, vol. 128, no. 12, pp. 3941-3961, 2000.

[14] M. Mandal, U. C. Mohanty, and S. Raman, "A study on the impact of parameterization of physical processes on prediction of tropical cyclones over the Bay of Bengal with NCAR/PSU mesoscale model," Natural Hazards, vol. 31, no. 2, pp. 391-414, 2004.
[15] R. G. Fovell and H. Su, "Impact of cloud microphysics on hurricane track forecasts," Geophysical Research Letters, vol. 34, no. 24, 2007.

[16] P. V. S. Raju, J. Potty, and U. C. Mohanty, "Sensitivity of physical parameterizations on prediction of tropical cyclone Nargis over the Bay of Bengal using WRF model," Meteorology and Atmospheric Physics, vol. 113, no. 3, pp. 125-137, 2011.

[17] X. Li and Z.Pu, "Sensitivity of numerical simulations of the early rapid intensification of Hurricane emily to cumulus parameterization schemes in different model horizontal resolutions," Journal of the Meteorological Society of Japan, vol. 87, no. 3, pp. 403-421, 2009.

[18] B. Xie and F. Zhang, "Impacts of typhoon track and Island topography on the heavy rainfalls in Taiwan associated with Morakot (2009)," Monthly Weather Review, vol. 140, no. 10, pp. 3379-3394, 2012.

[19] S. Brand and J. W. Blelloch, "Changes in the characteristics of typhoons crossing the island of Taiwan," Monthly Weather Review, vol. 102, no. 10, pp. 708-713, 1974.

[20] M. A. Bender, R. E. Tuleya, and Y. Kurihara, "A numerical study of the effect of island terrain on tropical cyclones.," Monthly Weather Review, vol. 115, no. 1, pp. 130-155, 1987.

[21] T. Yeh and R. L. Elsberry, "Interaction of Typhoons with the Taiwan orography. Part I: upstream track deflections," Monthly Weather Review, vol. 121, no. 12, pp. 3193-3212, 1993.

[22] T.-C. Yeh and R. L. Elsberry, "Interaction of Typhoons with the Taiwan Orography. Part II: continuous and discontinuous tracks across the island," Monthly Weather Review, vol. 121, no. 12, pp. 3213-3233, 1993.

[23] C. P. Chang, T. C. Yeh, and J. M. Chen, "Effects of terrain on the surface structure of typhoons over Taiwan," Monthly Weather Review, vol. 121, no. 3, pp. 734-752, 1993.

[24] L. M. Farfán and J. A. Zehnder, "An analysis of the landfall of Hurricane Nora (1997)," Monthly Weather Review, vol. 129, no. 8, pp. 2073-2088, 2001.

[25] C.-C. Wu, T.-H. Yen, Y.-H. Kuo, and W. Wang, "Rainfall simulation associated with Typhoon Herb (1996) near Taiwan. Part I: the topographic effect," Weather and Forecasting, vol. 17, no. 5, pp. 1001-1015, 2002.

[26] Y.-L. Lin, N. C. Witcraft, and Y.-H. Kuo, "Dynamics of track deflection associated with the passage of tropical cyclones over a mesoscale mountain," Monthly Weather Review, vol. 134, no. 12, pp. 3509-3538, 2006.

[27] G.-J. Jian and C.-C. Wu, "A numerical study of the track deflection of supertyphoon haitang (2005) prior to its landfall in Taiwan," Monthly Weather Review, vol. 136, no. 2, pp. 598$615,2008$.

[28] C.-C. Wu and Y.-H. Kuo, “Typhoons affecting Taiwan-Current understanding and future challenges," Bulletin of the American Meteorological Society, vol. 80, no. 1, pp. 67-80, 1999.

[29] C.-C. Wu, "Numerical simulation of typhoon Gladys (1994) and its interaction with Taiwan terrain using the GFDL hurricane model," Monthly Weather Review, vol. 129, no. 6, pp. 1533-1549, 2001.

[30] India Meteorological Department, "Report on cyclonic disturbances over North Indian Ocean during 2016. RSMC-Tropical cyclones, IMD, New Delhi," 2016.

[31] W. C. Skamarock, J. B. Klemp, J. Dudhi et al., Tech. Rep., A Description of the Advanced Research WRF Version 3. NCAR Technical Note, 2008. 
[32] S.-Y. Hong, J. Dudhia, and S.-H. Chen, "A revised approach to ice microphysical processes for the bulk parameterization of clouds and precipitation," Monthly Weather Review, vol. 132, no. 1, pp. 103-120, 2004.

[33] Z. I. Janjic, “The step-mountain eta coordinate model: further developments of the convection, viscous sublayer, and turbulence closure schemes," Monthly Weather Review, vol. 122, no. 5, pp. 927-945, 1994.

[34] S. H. Chen and W. Y. Sun, "A one-dimensional time dependent cloud model," Journal of the Meteorological Society of Japan, vol. 80, no. 1, pp. 99-118, 2002.

[35] J. Dudhia, S.-Y. Hong, and K.-S. Lim, "A new method for representing mixed-phase particle fall speeds in bulk microphysics parameterizations," Journal of the Meteorological Society of Japan, vol. 86A, pp. 33-44, 2008.

[36] B. S. Ferrier, Y. Jin, Y. Lin, T. Black, E. Rogers, and G. DiMego, "Implementation of a new grid-scale cloud and precipitation scheme in the NCEP Eta Model," in Proceedings of the in the 19th Conf. on Weather Analysis and Forecasting/15th Conf. on Numerical Weather, pp. 280-283, American Meteorological Society, 2002.

[37] S.-Y. Hong and J.-W. Lee, "Assessment of the WRF model in reproducing a flash-flood heavy rainfall event over Korea," Atmospheric Research, vol. 93, no. 4, pp. 818-831, 2009.

[38] J. Dudhia, "Numerical study of convection observed during the Winter Monsoon Experiment using a mesoscale twodimensional model," Journal of the Atmospheric Sciences, vol. 46, no. 20, pp. 3077-3107, 1989.

[39] M. J. Iacono, J. S. Delamere, E. J. Mlawer, M. W. Shephard, S. A. Clough, and W. D. Collins, "Radiative forcing by long-lived greenhouse gases: calculations with the AER radiative transfer models," Journal of Geophysical Research D: Atmospheres, vol. 113, no. 13, Article ID D13103, 2008.

[40] F. Chen and J. Dudhia, "Coupling an advanced land surface-hydrology model with the Penn State-NCAR MM5 modeling system. Part II: preliminary model validation," Monthly Weather Review, vol. 129, no. 4, pp. 587-604, 2001.

[41] D. L. Douluri and K. Annapurnaiah, "Impact of microphysics schemes in the simulation of cyclone hudhud using WRF-ARW model," International Journal of Oceans and Oceanography, vol. 10, no. 1, pp. 49-59, 2016.

[42] S. Chen, Y.-K. Qian, and S. Peng, "Effects of various combinations of boundary layer schemes and microphysics schemes on the track forecasts of tropical cyclones over the South China sea," Natural Hazards, vol. 78, no. 1, article A005, pp. 61-74, 2015.

[43] P. V. S. Raju, J. Potty, and U. C. Mohanty, "Prediction of severe tropical cyclones over the Bay of Bengal during 2007-2010 using high-resolution mesoscale model," Natural Hazards, vol. 63, no. 3, pp. 1361-1374, 2012.

[44] K. B. R. R. Hariprasad, C. V. Srinivas, A. B. Singh, S. Vijaya Bhaskara Rao, R. Baskaran, and B. Venkatraman, "Numerical simulation and intercomparison of boundary layer structure with different PBL schemes in WRF using experimental observations at a tropical site," Atmospheric Research, vol. 145-146, pp. 27-44, 2014.

[45] G. Asnani, "Tropical meteorology, vols. 1 and 2, published by Prof. G.C. Asnani,c/o Indian Institute of Tropical Meteorology, Dr. Homi Bhabha Road, Pashan, Pune- 411008, India Betts AK, Miller MJ (1986) A new convective adjustment scheme. Part II: single column test," 1993.

[46] X. Fang, Y.-H. Kuo, and A. Wang, "The impacts of Taiwan topography on the predictability of Typhoon Morakot's record-breaking rainfall: a high-resolution ensemble simulation," American Meteorological Society, vol. 26, no. 5, pp. 613633, 2011.

[47] H. A. Ramsay, L. M. Leslie, P. J. Lamb, M. B. Richman, and M. Leplastrier, "Interannual variability of tropical cyclones in the Australian region: role of large-scale environment," Journal of Climate, vol. 21, no. 5, pp. 1083-1103, 2008.

[48] Y. Yang and Y.-L. Chen, "Effects of terrain heights and sizes on island-scale circulations and rainfall for the island of Hawaii during HaRP," Monthly Weather Review, vol. 136, no. 1, pp. 120146, 2008. 

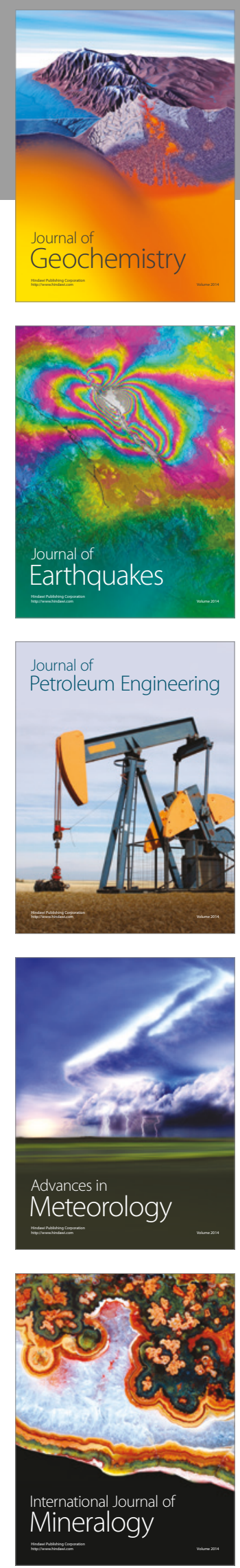
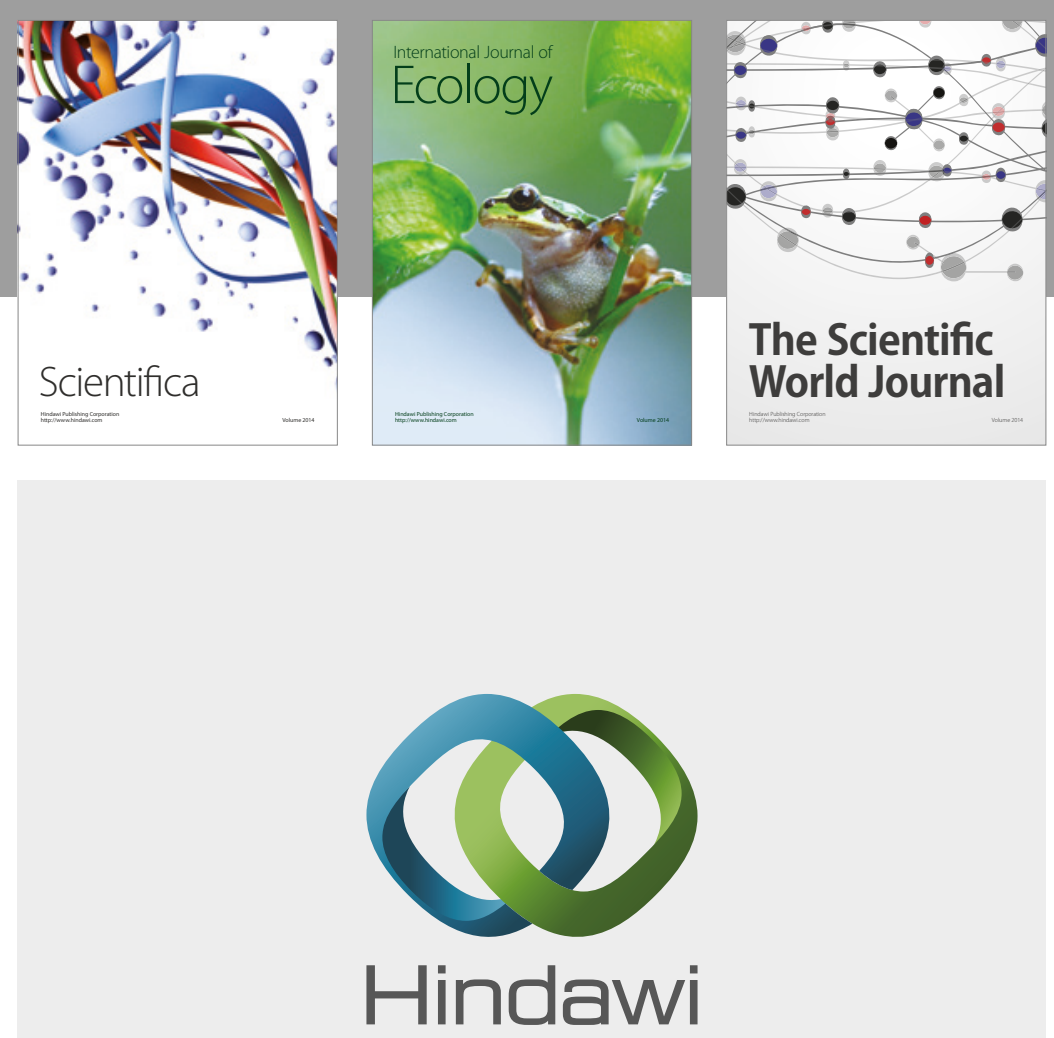

Submit your manuscripts at

https://www.hindawi.com
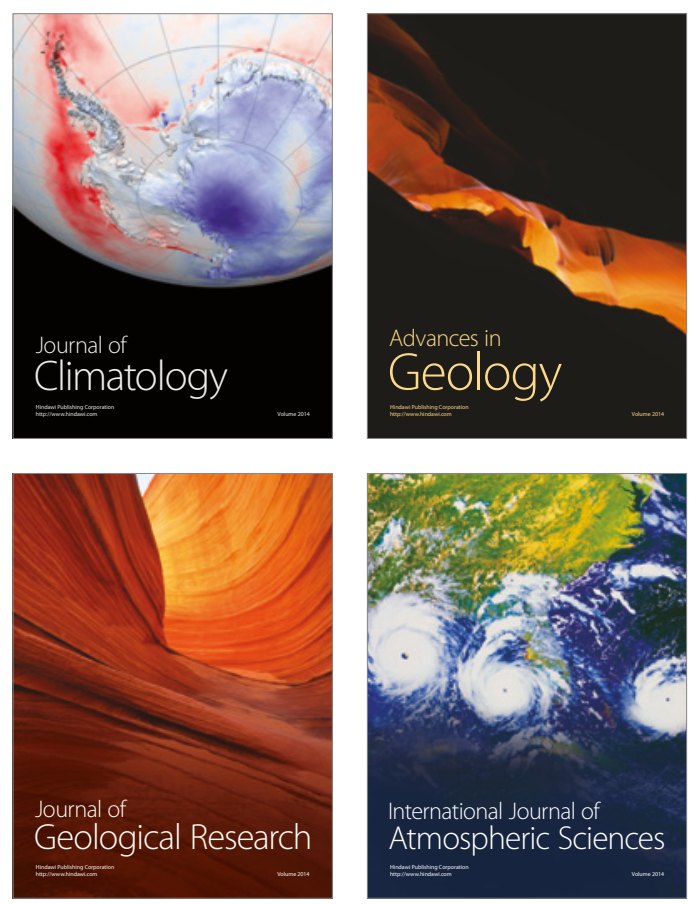

The Scientific

World Journal
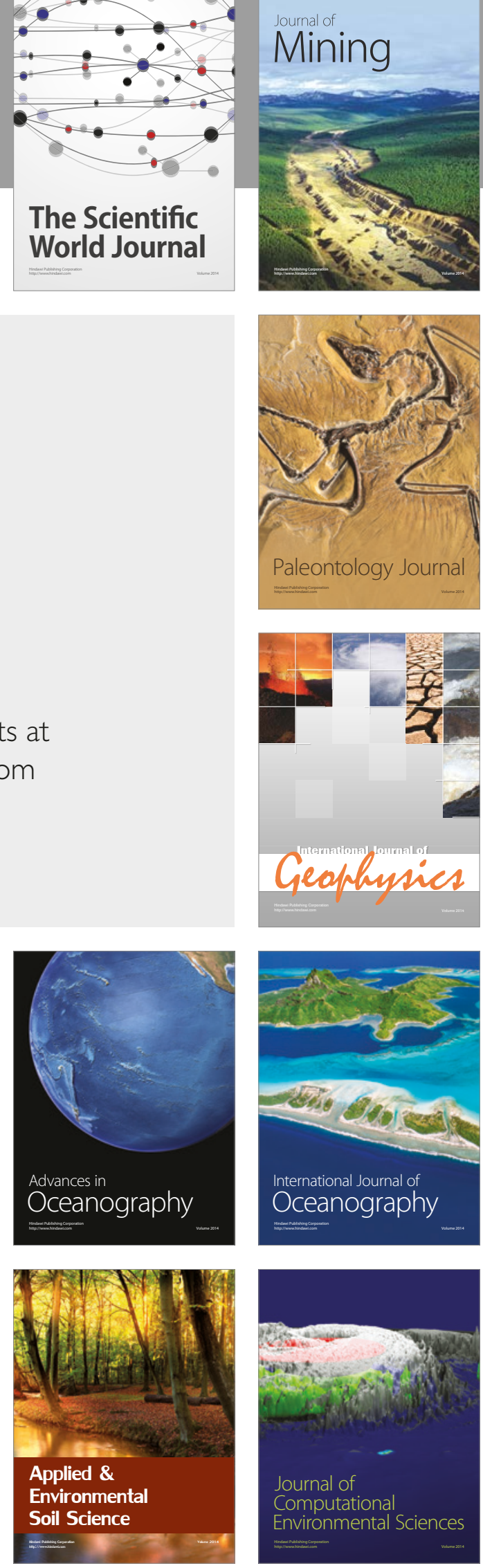